Social Responses to Expressive Suppression: The Role of Personality Judgments

\author{
Allison M. Tackman \\ Sanjay Srivastava \\ University of Oregon
}

In press, Journal of Personality and Social Psychology

Note: This is a pre-publication manuscript. The final published version may differ slightly. 


\begin{abstract}
Why do people who suppress their emotion-expressive behavior have difficulty forming close and supportive relationships? Previous studies have found that suppression disrupts the dynamics of social interactions and existing relationships. We evaluated a complementary hypothesis: that suppression functions as a behavioral cue that leads others to form negative personality impressions of suppressors, even at zero acquaintance. In 2 experiments, participants reported personality judgments and other impressions of targets who either suppressed or expressed their emotion-expressive behavior to amusing or sad film clips. In replicated findings, targets who suppressed either amusement or sadness were judged as less extraverted, less agreeable, and more interpersonally avoidant and anxious than targets who expressed, and participants were less interested in affiliating with suppressors compared to expressers. Effects were amplified when targets suppressed amusement (compared to sadness) and when participants knew the emotional context (compared to when they did not) and thus could form expectations about what emotions targets should be showing. Extraversion and agreeableness judgments mediated the effect of suppression on participants' disinterest in affiliating. In Study 2, which extended Study 1 in several ways, effects were pronounced for the enthusiasm aspect of extraversion and for the compassion aspect of agreeableness. We also found evidence that judgments of suppressors do not simply fall between neutral and fully-expressing targets; rather, judgments of suppressors are qualitatively different. We discuss implications for understanding the social consequences of emotion regulation, in particular how beyond disrupting relationships, suppression may prevent some relationships from even forming in the first place.
\end{abstract}

Keywords: emotion, emotion regulation, interpersonal perception, personality judgment, relationships 
Social Responses to Expressive Suppression: The Role of Personality Judgments

When people have emotions that they do not want to be having, or in a time and place they do not want to have them, they can use a variety of emotion regulation strategies to change their emotions. One common strategy is expressive suppression (hereafter just "suppression”), in which people attempt to inhibit the overt signs of an emotion that they are feeling. Suppression is used frequently in daily life, typically in the presence of other people (Gross, Richards, \& John, 2006). Intuitively it may seem appealing to sometimes hide one's emotions from others. Yet numerous studies have found that suppression leads to difficulties forming close relationships and obtaining social support (Butler et al., 2003; Srivastava, Tamir, McGonigal, John, \& Gross, 2009). Thus, despite being a common strategy, suppression is a socially costly one.

Why is suppression so bad for social functioning? There are probably multiple answers to that question. Previous research has focused on how suppression might disrupt the reciprocal dynamics of social interactions. The goal of the present manuscript is to investigate a second possible mechanism. We propose that suppression is a behavioral cue that other people use to form judgments of the suppressor's personality. Our overall hypothesis is that when other people observe someone using suppression, they form negative impressions of the suppressor's enduring personality traits and interpersonal motivations. This impression-formation process can take place outside of and even prior to any social interaction - such as in a zero-acquaintance context. Such negative impressions may then reduce others' desire to affiliate with suppressors, producing the social costs documented in previous studies.

The present research complements and builds on previous research on suppression, by examining in more depth how other people react to suppressors. We report two experiments in which we investigated critical parts of our hypothesis. In both experiments, participants viewed 
videos of targets who either used suppression or reacted naturally during an emotion-eliciting event. The participants then reported their impressions of the targets. We measured how a target's suppression affected judgments of personality traits and interpersonal motivations, as well as how it affected participants' desire to affiliate with suppressors. In addition, in moderator analyses we studied how the effects of suppression were similar or different when different emotions were being suppressed (amusement or sadness), and when participants either were or were not given context cues about what emotions the targets were likely to be expressing.

\section{Suppression in Social Contexts}

Suppression is somewhat unusual among emotion regulation strategies because it targets expressive behavior, which is readily observable by others and ordinarily functions as a social signal. A number of studies have shown that suppressors' efforts at inhibiting their emotionexpressive behavior are at least partially successful: both correlational and experimental studies have found that when people try to suppress, they display substantially less positive and negative emotion-expressive behavior, as assessed both by expert coding and peer reports (Gross, 1998; Gross \& John, 2003; Gross \& Levenson, 1993, 1997).

Perhaps because it might sometimes seem useful to hide one's emotions, suppression is used frequently in daily life, especially in social situations (Gross et al., 2006). However, across multiple studies using diverse methods, evidence has accumulated that suppression is a socially costly strategy. For example, in a longitudinal study of students transitioning to college, individual differences in suppression before the transition, as well as increases in suppression from before to after the transition, predicted difficulties forming close relationships and getting social support in the new college environment (Srivastava et al., 2009). And in experiments where some participants were instructed to use suppression during a conversation, their 
interaction partners became more stressed (had elevated blood pressure) during the conversation and later reported feeling less interested in affiliating with the suppressors (Butler et al., 2003). The negative social consequences of suppression have been observed in individuals with Western European and Asian cultural values, though they are stronger in the former (Butler, Lee, \& Gross, 2007; see also Soto, Perez, Kim, Lee, \& Minnick, 2011). Thus, across multiple studies and paradigms, researchers have found that other people respond negatively to suppressors, and this impairs suppressors' ability to create and maintain healthy relationships.

\section{Suppression as a Behavioral Cue for Social Perceivers}

Why is suppression so socially costly? To date, a number of studies have developed evidence for a relationship dynamics account (Butler et al., 2003; English \& John, 2013; Impett et al., 2012). The relationship dynamics account focuses on how suppression can alter or disrupt the bidirectional dynamics between people during social interactions. For example, because suppression is cognitively taxing, it can diminish the suppressor's attention and responsiveness to a partner (Butler et al., 2003; Richards, Butler, \& Gross, 2003). It can make suppressors feel inauthentic in interactions, leading them to withdraw from the kinds of reciprocal disclosure that would otherwise promote intimacy and closeness (English \& John, 2013). Suppression during interactions between romantic partners can also make the partner of a suppressor feel detached or unappreciated (Impett et al., 2012). The relationship dynamics account provides a rich explanation of how suppression can derail interactions in existing relationships.

However, although the relationship dynamics account is well supported by evidence, it may not be the only way that suppression affects social functioning. For the present investigation, we considered a complementary possibility: that suppression can also be a problem before a relationship is even established, by biasing first impressions and possibly preventing 
close connections from forming. Specifically, we propose that suppression functions as a behavioral cue that others use to form impressions of the suppressor's personality. When others see someone using suppression, they interpret the suppressor's behavior - the behaviors that are present, or the behaviors that are absent relative to expectations - as indicative of the suppressor's personality traits and interpersonal motivations.

Our approach builds on research into "zero-acquaintance" and "thin-slice" judgments of personality (e.g., Albright, Kenny, \& Malloy, 1988; Ambady, Bernieri, \& Richeson, 2000; Borkenau, Mauer, Riemann, Spinath, \& Angleitner, 2004). This work has shown that across a wide range of contexts and attributes, perceivers form judgments of targets' personality traits from a few minutes or even seconds of social behavior (e.g., Ambady, Hallahan, \& Rosenthal, 1995; Borkenau \& Liebler, 1992; Carney, Colvin, \& Hall, 2007).

Thin-slice judgments can be based on many different behavioral cues (Gosling, 2008). One important class of cues is emotion-expressive behavior. A number of studies have shown that when people perceive others' emotional expressions, they do more than just infer targets' current emotional states - they "go beyond the information given" and infer enduring personality traits. For example, targets that smile are judged to be high in trait affiliation, and targets that show contempt or disgust are judged to be low (Arya, Jefferies, Enns, \& DiPaola, 2006; Knutson, 1996). Targets that display happiness are judged to be more extraverted, agreeable, and emotionally stable than targets displaying sadness (Hall, Gunnery, \& Andrzejewski, 2011). Building on this previous work, we reasoned that if emotional expressions affect personality judgments, then suppression of expressions might also have an effect.

What specific personality judgments might we expect perceivers to form of targets who use suppression? Among the Big Five traits, extraversion and agreeableness are both likely 
candidates because of their relevance to social interactions and relationships (Wiggins \& Trapnell, 1996). We also posited that suppression would affect more contextualized personality judgments, specifically judgments about a target's attitudes and motivations about close relationships.

\section{Extraversion}

Suppression leads to visible reductions in positive emotion-expressive behavior (Gross \& John, 2003; Gross \& Levenson, 1997), and perceivers use positive emotional expressions as cues when judging extraversion (Borkenau, Brecke, Möttig, \& Paelecke, 2009; Kenny, Horner, Kashy, \& Chu, 1992). We therefore hypothesized that perceivers would use suppressors' reduced positive expressions, and perhaps other cues specific to suppression, to infer that suppressors are less extraverted than people who do not suppress.

\section{Agreeableness}

Suppression is only weakly associated with agreeableness (Gross \& John, 2003). Why might a target's suppression nevertheless affect judgments of agreeableness? Whereas extraversion is associated with many observable behaviors, agreeableness is defined much more by intentions and motivations (Pytlik Zillig, Hemenover, \& Dienstbier, 2002). These intentions and motivations have substantial consequences for other people: for example, agreeable people are more motivated to maintain positive relations with others (Graziano \& Eisenberg, 1997), are more likely to cooperate with others, and are less likely to cheat or defect in ways that harm others (Denissen \& Penke, 2008). Thus, perceivers are especially attuned to potential signals of agreeableness (Ames \& Bianchi, 2008). Emotion-expressive behavior is one way that people signal mental states and future intentions, and when people express their emotions (thus signaling their intentions) that can be interpreted as a signal of prosocial motivation (Brown \& 
Moore, 2002). So conversely, when targets appear to be suppressing, others may interpret that as a disinterest in positive relationships and possibly even as an attempt to conceal bad intentions which may form a basis for judgments of low agreeableness.

\section{Interpersonal Motivation}

In addition to broad personality impressions, we were interested in what inferences perceivers would draw about suppressors' motivational stance toward close relationships: specifically, whether suppressors seem avoidant or distant, and whether they seem anxious about getting close to others. These two dimensions, avoidance and anxiety, characterize important individual differences in relationship orientations in adulthood (Fraley \& Waller, 1998). Emotion-expressive behavior and disclosure is important in the formation of close relationships in myriad ways, including signaling approachability (Simpson, Gangestad, \& Nations, 1996), eliciting social support (Eisenberg, Fabes, Schaller, \& Miller, 1989), and signaling a willingness to support others (Lin, 1986). Because pursuing close relationships can require costly social investments, perceivers may be attuned to expressive behavior and emotional disclosure, or the lack of it, as an indication of how a target is likely to respond to overtures toward closeness. On this basis, we hypothesized that perceivers would interpret suppression as a sign of disinterest and avoidance of close relationships. Anxiety-related traits are difficult to decipher in others (Vazire, 2010); we examined impressions of relationship anxiety but did not have strong hypotheses about it.

\section{Using Trait Judgments to Decide About Affiliation}

All of the personality traits typically studied by psychologists, including the Big Five, contain information that perceivers use to make important social decisions about targets (Saucier \& Srivastava, in press; Srivastava, 2010). Since traits are temporally stable, perceivers use trait 
judgments to predict the target's likely future behavior and intentions (Heyman \& Gelman, 1999). One important decision people make is whether to pursue a close relationship with another person. Previous research has found that others are less interested in affiliating with suppressors (Butler et al., 2003). We expected to replicate this finding, and we hypothesized that the negative trait judgments people form of suppressors might help explain the effect.

\section{Potential Moderators: Specific Emotions and Context Cues}

Are the effects of suppression on others' personality judgments always the same? Previous research on suppression has typically compared its presence to its absence, or contrasted suppression to other emotion regulation strategies like cognitive reappraisal. Relatively less attention has been paid to contextual variability in the effects of suppression.

We considered two factors that might lead to variability in the effects of suppression on personality judgments. The first factor was which emotion was being suppressed: does it make a difference which emotion a target is suppressing? A second factor was contextual information: does it matter whether perceivers know what emotion-eliciting event the target is reacting to? We examined both of these in our studies by varying the emotion being suppressed and whether perceivers knew the emotion-eliciting context.

\section{Specific Emotions: Amusement Versus Sadness}

Does it matter what emotion a suppressor is suppressing? Much of the literature on the social consequences of suppression has not differentiated among specific emotions, and when emotions have been examined separately the effects are often similar. For example, in one study that looked at suppression of positive emotions and negative emotions separately in a post hoc analysis, they were found to have effects in the same direction (Srivastava et al., 2009). Thus, we broadly expected that the simple effects of suppression would be directionally similar - for 
example, that suppressors would be perceived as less extraverted regardless of what emotion they were suppressing.

However, just because the qualitative direction of two effects is similar, it is still possible that the relative magnitude may not be the same. For the present studies we focused on two specific emotions, one positively valenced (amusement) and one negatively valenced (sadness). Why might perceivers form different impressions of people suppressing amusement than people suppressing sadness? First, suppression of sadness is more common in daily life than suppression of amusement (Gross et al., 2006). Thus, suppression of amusement may simply be more salient by virtue of being unusual. Second, research on display rules - culturally learned rules that govern the display of emotion in social circumstances - suggests that in individualistic cultural contexts (such as where our experiments took place), the expression of positive emotions is considered more socially appropriate than the expression of negative emotions (Matsumoto et al., 2008). Thus, when perceivers see someone suppressing sadness, they may interpret it as more consistent with following general social norms, and thus less diagnostic of an individual's distinct personality.

\section{Context Cues and Expectations}

What information do perceivers use to form judgments about suppressors? Expressive behavior is an important component of emotions, but emotions do not occur in a vacuum - they have a situational context. We investigated whether perceivers might use context cues to form expectations about what a target should be expressing and then interpret targets' behavior relative to those expectations (Burgoon, 1993). Expectations of what emotions people should be displaying vary across many levels of contexts, including cultures (Matsumoto et al., 2008), roles (Morris \& Feldman, 1996), and relationships (Burgoon, 1993). Context-based expectations might 
be used as a point of reference for judging targets' nonverbal behavior. In our studies we focused on a relatively narrow and proximal context: the emotion-eliciting event. We manipulated whether perceivers saw the targets' emotional behavior alongside the emotion-eliciting event, versus only seeing the targets' behavior. If the effects of suppression are changed by the addition of contextual information, this suggests that perceivers use context information as well as targets' nonverbal behavior to make personality judgments of suppressors.

\section{Judgments of Targets' Emotional Experience and Expression}

The focus of this investigation was how suppression affects judgments of personality and decisions about affiliation. However, we also collected and analyzed judgments of what emotions the targets were experiencing (Studies 1 and 2) and expressing (Study 2). We used these judgments in three ways. First, the emotion judgments served as a basic validation check on our stimuli: we expected that perceivers who saw targets suppressing amusement or sadness would judge them as experiencing and expressing less amusement and sadness compared to targets expressing these emotions. Second, the emotion judgments provided additional interpretive information about the perceivers' impressions of the targets, by showing whether the targets suppressing their emotions appeared to be relatively unfeeling, inexpressive, or both. Third, we examined the extent to which the effects of suppression on personality judgments and interest in affiliating with the targets were independent of, versus depended on (were mediated by), the emotion experience and expression judgments. These analyses, along with comparisons with a neutral control condition in Study 2, helped explicate how emotion perceptions relate to perceivers' judgments about personality traits, interpersonal motivation, and affiliation. Did those judgments merely reflect an impression that suppressors were emotionally unmoved or unexpressive about the stimuli, or was there something particular or different about suppression? 


\section{Overview of Studies}

To examine how suppression affects personality judgments, we ran two experiments in which participants served as perceivers and saw videos of targets who were viewing amusing or sad film clips. The targets were either trying to suppress their emotional reactions or reacting naturally. Some participants were able to see and hear the emotion-eliciting film clips, and thus knew what the targets were reacting to; other participants were given no contextual information from which to form expectations about the targets' emotion-expressive behavior. After viewing each video, the participants reported their impressions of the target, including emotional experience, Big Five personality impressions, interpersonal avoidance and anxiety, and interest in affiliating with the target.

Study 2 was designed to directly replicate the key findings from Study 1 and extend them in several ways. In Study 2 we added an additional condition in which the targets watched an emotionally neutral film clip (a screensaver); this allowed us to see whether participants formed different judgments of a target who was actively suppressing versus a target who was merely expressionless. In addition to measuring the targets' emotional expression, Study 2 also added finer-grained measurement of the personality trait judgments, allowing us to better understand how suppression affected different aspects of the Big Five trait domains.

\section{Study 1}

\section{Method}

Participants and procedure. The participants were $N=149$ undergraduates from a large university in the northwestern United States (55\% female; $M$ age $=20$ years). The sample size was determined by setting a goal of running at least 100 participants and then continuing data collection until the end of the academic term in which the study took place (since it was 
relatively inexpensive and convenient to do so). No data were analyzed until data collection was complete. The ethnic composition of the sample was similar to the general student population at the university: 1\% American Indian/Alaska Native, 14\% Asian, 3\% Native Hawaiian or Other Pacific Islander, 1\% Black or African American, 76\% White, and 5\% other (participants were allowed to mark more than one category). In exchange for their participation, participants received credit in partial fulfillment of a course requirement. The protocol was approved by the authors' institutional review board.

The experiment had a 2 (suppress vs. express, within-subjects) $\times 2$ (amusement vs. sadness, within-subjects) $\times 2$ (no-context vs. context, between-subjects) factorial design. Upon arrival to the lab, participants were individually seated in front of a computer and asked to sign a statement of informed consent. At the beginning of the experiment, participants read instructions on the computer informing them that they would watch several videos, and that each video would show somebody who was watching a scene from a movie. They were instructed to watch the videos carefully, paying attention to the person who was watching the movie. Over the course of the experiment, each participant watched four videos in counterbalanced order: express amusement, express sadness, suppress amusement, and suppress sadness. Each video showed the face of a different target person who was either suppressing or expressing their emotionexpressive behavior while watching either an amusing or sad film clip. Participants were also randomly assigned (between-subjects) to either a no-context condition $(n=75)$ in which they only saw the targets' facial behavior and heard audio from the targets, or a context condition $(n=$ 74) in which they could also hear and see the amusing or sad film clip that the targets were responding to (see Figure 1 for examples of stimuli). After watching each video, participants reported their judgments of the target's emotion experience, personality judgments of the target, 
and interest in affiliating with the target. They also made other ratings, including filler items and items related to other research questions. After the experiment was over, participants were individually debriefed. The entire procedure took about 45 minutes to complete.

Video stimuli and counterbalancing. Across the entire experiment there were 32 different videos. Each video was approximately three minutes in length, shown in color, and had sound. To create the express amusement videos, we videotaped four White target persons (two male and two female) while they watched and reacted naturally to an amusing film clip from the 1989 movie When Harry Met Sally (Sally faking an orgasm in a diner). For the express sadness videos, the same target persons watched and reacted naturally to a sad film clip from the 1979 movie The Champ (T.J. watching his father die). The amusing and sad film clips have been shown to elicit high levels of the respective focal emotions and low levels of all other emotions (Gross \& Levenson, 1995; Rottenberg, Ray, \& Gross, 2007). To create the suppress amusement and suppress sadness videos, the four targets each watched the same film clips again (one week later) but were instructed to suppress their emotion-expressive behavior. This resulted in a total of 16 videos (four target persons appearing in each of the four types of videos). In the express videos the targets displayed facial and vocal expressions of amusement and sadness, and in the suppress videos the targets appeared mostly neutral with small signs of amusement or sadness occasionally leaking through. In the Results section we report analyses that confirm this observation, and we investigate it further in Study 2 when we compare suppress targets to neutral targets.

For the between-subjects manipulation of participants' expectations, we created two versions of each of the 16 videos described above. For the no-context condition, participants only saw the facial reactions and heard the vocal responses of the targets, with no information about 
what the targets were responding to (targets wore earbuds, so the audio from the film clips was not audible). For the context condition, we inserted the amusing or sad film clip that the targets were watching and mixed the audio from the film clip with the audio of the targets' responses, so that participants could see and hear the film clip at the same time as the targets' facial and vocal reactions.

Target person and order were counterbalanced using a Graeco-Latin square design. As a result, each participant saw all four target persons, each one in a different condition (i.e., express amusement, express sadness, suppress amusement, suppress sadness). Across the entire experiment each target person appeared with about equal frequency in all possible conditions, and all targets and conditions appeared in all four serial positions. This was to ensure that the experimental variables were not confounded with stable target characteristics (e.g., hairstyle, facial structure, etc.) or with serial position.

Measure of perceived emotional experience. We asked participants to indicate the extent to which each of the four targets was experiencing amusement and sadness during each video, using a scale from 1 (not at all) to 5 (extremely). These items were mixed with other emotion items as fillers to disguise our interest in amusement and sadness (which was particularly important in the no-context condition).

Measure of judgments of Big Five traits. The participants' judgments of targets' Big Five personality traits were measured using the 10-item short version of the Big Five Inventory (BFI-10; Rammstedt \& John, 2007). Each Big Five scale consists of one true-scored and one reversed-scored item. For example, items that measure extraversion are "Is outgoing, sociable" and "Is reserved," and items that measure agreeableness are "Is generally trusting" and "Tends to find fault with others." (Complete text of all items for all measures in Study 1 and 2 is reported 
in Supplement 1.) Participants rated how well each item described each target on a scale from 1 (disagree strongly) to 5 (agree strongly).

The BFI-10 was designed to cover complementary aspects of each of the broad Big Five domains, and this was given higher priority than maximizing internal consistency via redundant content, so alpha coefficients (which are an index of internal consistency) underestimate true reliability (John \& Soto, 2007; Schmitt, 1996) and were expected to be lower than in traditional full-length scales. Across the four within-subject conditions, alphas for the 2-item extraversion scale ranged from .58 to .69; agreeableness from .44 to .61 ; conscientiousness from .53 to .61 ; neuroticism from .44 to .70; and openness to experience from .13 to .24. As noted, these internal consistency statistics were not unexpected, and the BFI-10 has previously been found to be reliable in self-reports using other approaches such as test-retest (Rammstedt \& John, 2007).

Measure of judgments of relationship motivations. We measured judgments of targets' avoidant and anxious orientations towards close relationships with items adapted from the Experiences in Close Relationships questionnaire (ECR; Brennan, Clark, \& Shaver, 1998). The ECR was originally designed as a self-report measure of romantic attachment style, with 18 avoidance items and 18 anxiety items. To adapt it to measure social judgments, we reworded items to be in the third person and to describe the target's general orientation towards close relationships (not any specific kind of relationship). Due to the number of targets and limited participant time, we selected the four avoidance items and four anxiety items with the highest item-total correlations on their respective scales in previous research. This resulted in two social perception scales: a 4-item avoidance scale that refers to discomfort with closeness and dependency on others (e.g., "This person prefers not to show others how he/she feels deep down") and a 4-item anxiety scale that refers to fear of rejection and abandonment (e.g., "This 
person worries a fair amount about losing people close to him/her”). Items were rated on a scale from 1 (disagree strongly) to 7 (agree strongly). For the avoidance scale, $\alpha$ s ranged from .68 to .82 ; for the anxiety scale, $\alpha$ s ranged from .73 to .76 .

Measure of interest in affiliating. Participants' interest in affiliating with the targets was measured with a 5-item composite. We chose the five items by reviewing affiliation items used by Butler et al. (2003) and Gross and John (2003) and using or adapting ones that were appropriate for a zero-acquaintance study. The five items were: (1) "I like this person," (2) "I would enjoy talking to this person," (3) "I would enjoy spending time with this person," (4) "This person is the type of person I could get along with," and (5) "This person is the type of person I could become close friends with.” Participants indicated their agreement or disagreement with each item on a scale from 1 (disagree strongly) to 7 (agree strongly). Alpha reliability for the affiliation composite ranged from .92 to .95 .

Analyses. To aid in interpretation, all dependent measures were rescaled with a linear transformation to Percent of Maximum Possible (POMP) scores, giving them a theoretical range from 0 to 100 (Cohen, Cohen, Aiken, \& West, 1999).

We analyzed the data using linear regression models (Judd, McClelland, \& Ryan, 2009), with suppression vs. expression and amusement vs. sadness as within-subjects factors, and nocontext vs. context as a between-subjects factor. Analyses also included a set of contrast codes to account for the four counterbalancing conditions. For each analysis we report three statistics: an unstandardized model-estimated difference $(D)$, representing the effect in POMP units of an experimental factor after adjusting for other experimental variables; a 95\% confidence interval of $D$; and a standardized effect size, $d$, calculated as the mean difference divided by the average within-cell standard deviation (sometimes abbreviated as $d_{a v}$; Cumming, 2012; Lakens, 2013). 
Several formulas of $d$ can be used for repeated-measures designs; we calculated $d$ in this way because our focus was on the difference between conditions, not on how subjects changed as they moved across conditions (see Morris \& DeShon, 2002).

\section{Results}

Judgments of emotional experience. What emotions did participants think the targets were actually experiencing? Means and standard deviations of participants' judgments of the targets' emotion experience are shown in Supplement 2. Targets suppressing amusement were judged as feeling substantially less amused than targets expressing amusement regardless of context condition. The unstandardized model-estimated difference between the suppress and express targets was $D=-53.01,95 \%$ CI $[-59.51,-46.50]$ in the no-context condition and $D=-$ $57.46,95 \% \mathrm{CI}[-62.76,-52.16]$ in the context condition, meaning that the difference was about half of the theoretical range of the 0-100 scale. The standardized difference was Cohens $d=-$ 2.28 for the no-context condition and $d=-2.66$ for the context condition, indicating very large effects by Cohen's (1992) benchmarks. Similarly, targets suppressing sadness were judged as feeling substantially less sad than targets expressing sadness regardless of context condition: nocontext condition, $D=-27.30,95 \%$ CI $[-33.74,-20.85], d=-0.88$; context condition, $D=-33.30$, $95 \%$ CI [-40.61, -25.98], $d=-1.29$.

\section{Main effects of suppression on personality judgments and affiliation. We}

hypothesized that suppress targets (in comparison to express targets) would be judged as (1) less extraverted, (2) less agreeable, and (3) more avoidant in close relationships. Table 1 shows the means and standard deviations of participants' judgments in all conditions. The hypothesized effects were all medium or large: suppressors were judged to be less extraverted than expressers, $D=-24.51,95 \%$ CI $[-27.79,-21.24], d=-1.09$; less agreeable, $D=-9.75,95 \%$ CI [-12.48, - 
7.02], $d=-0.57$; and more avoidant in close relationships, $D=15.15,95 \% \mathrm{CI}[12.50,17.79], d=$ 1.00. Suppressors were also judged to be more anxious in close relationships, $D=5.20,95 \% \mathrm{CI}$ $[3.09,7.32], d=0.36$.

Although not the focus of this investigation, we also explored the main effects of suppression on judgments of the other Big Five personality traits. Suppressors were judged to be less open to experience, $D=-10.83,95 \% \mathrm{CI}[-13.55,-8.12], d=-0.67$; and less conscientious, $D$ $=-4.70,95 \% \mathrm{CI}[-7.19,-2.22], d=-0.28$. Suppress and express targets were not judged to be much different in neuroticism, $D=2.40,95 \%$ CI $[-0.77,5.58], d=0.11$.

Drawing from previous research, we also hypothesized that participants would be less interested in affiliating with suppressors compared to expressers. The data showed a large effect in the predicted direction, $D=-16.81,95 \%$ CI $[-19.72,-13.91], d=-0.89$.

To help in interpreting these findings, we examined the extent to which the effects of suppression on the personality judgments and interest in affiliating with the targets were attributable to judgments about emotional experience. We ran a series of mediated simple effects analyses (separately by focal emotion, sadness or amusement, matching the judged emotion to the stimulus condition) in which we decomposed the effects of suppression into two paths: an indirect path mediated by judgments of emotional experience, and a direct (unmediated) path controlling for perceived emotional experience. We ran these analyses for judgments of extraversion, agreeableness, avoidance, anxiety, and interest in affiliating; full results are reported in Supplement 3. In almost all cases the direct effect remained substantial, indicating that the effects of suppression could not entirely be attributed to the suppress targets appearing unfeeling. The exception was for judgments of agreeableness where the results were more 
ambiguous: in both emotion conditions the total effect was somewhat evenly split between the direct and indirect (mediated) paths but both were somewhat equivocal.

What about moderators? As can be seen in Table 1, the differences between the suppress and express targets were in the same direction regardless of the levels of the other variables. But we expected that the magnitude of the difference might be moderated by which emotion was being suppressed and by the presence of context cues. We next report interaction analyses for judgments of extraversion, agreeableness, attachment, and interest in affiliation. (For interested readers, means, standard deviations, and interaction effects for openness, conscientiousness, and neuroticism, although not the focus of this investigation, are reported in Supplement 4.)

Interactions with emotion. We compared the effects of suppression (vs. expression) when targets were viewing the amusing film clip to when they were viewing the sad one. For judgments of extraversion, agreeableness, and both types of insecure attachment in close relationships, the effects of suppression were stronger for amusement. The interaction effect can be expressed as a difference of differences (that is, the difference between the suppression effect in the amusement condition versus the suppression effect in the sadness condition). For extraversion, this effect was $D=-20.33,95 \%$ CI $[-26.88,-13.78], d=-0.89$, meaning that the effect of suppression (verses expression) was about 20 scale points larger in the amusement condition than in the sadness condition. For agreeableness, the interaction effect was $D=-9.92$, 95\% CI [-14.99, -4.86], $d=-0.57$; for avoidant attachment, $D=12.30,95 \%$ CI $[8.15,16.45], d=$ 0.81 ; and for anxious attachment, $D=9.64,95 \% \mathrm{CI}[5.69,13.59], d=0.66$. In addition, the effect of suppression on interest in affiliating was also greater for amusement than for sadness, $D$ $=-11.80,95 \%$ CI $[-16.78,-6.82], d=-0.61$. To illustrate, Figure 2 shows the suppression-byemotion interactions for extraversion and agreeableness (the other interactions were similar in 
form). In summary: all of the effects of suppression on participants' personality judgments and interest in affiliating with the targets were greater for targets suppressing vs. expressing amusement than for targets suppressing vs. expressing sadness.

Interactions with context cues. We compared the effects of suppression (vs. expression) when we gave participants context cues that allowed them to form expectations about what emotions targets should be expressing, versus when participants had no context cues and had to rely only on targets' behavior. For judgments of extraversion and agreeableness, the effects were amplified when context cues were present: for extraversion, the difference of differences (that is, the difference between the suppression effect in the context condition verses the suppression effect in the no-context condition) was $D=-8.16,95 \%$ CI $[-14.72,-1.61], d=-0.37$; for agreeableness, $D=-7.92,95 \% \mathrm{CI}[-13.38,-2.45], d=-0.45$. These effects are illustrated in Figure 3, which shows that suppressers were judged to be less extraverted and agreeable than expressers, and this was especially the case when participants saw the emotion-eliciting context that the targets were responding to.

Evidence of this 2-way interaction was weaker and more equivocal for judgments of both types of insecure attachment in close relationships. For avoidant attachment, the effect was $D=$ $3.77,95 \% \mathrm{CI}[-1.51,9.06], d=0.25$; and for anxious attachment, $D=0.79,95 \% \mathrm{CI}[-3.44,5.01]$, $d=0.07$. In both cases the point estimate was in the predicted direction but the confidence intervals were consistent with effects in either direction.

Finally, the effect of suppression on interest in affiliating was also amplified by the presence of context cues, $D=-8.66,95 \%$ CI $[-14.47,-2.85], d=-0.47$.

Three-way interactions. Although the analyses of the three-way interactions among suppression, emotion, and context cues were not the focus of our investigation, we briefly report 
them here for completeness. Considering that the effect of suppression was greater for amusement (vs. sadness) and when participants expected the targets to show emotion-expressive behavior (vs. when they did not), it is possible that the suppression-by-emotion interaction may be more pronounced in the context condition than in the no-context condition. In other words, the amplifying effect of participants' expectations may apply to the suppression-by-emotion interaction.

For all of the personality judgments examined in Study 1, as well as for participants' interest in affiliating with the targets, the point estimates of effects were in that direction; but only in one case did the confidence interval include only effects in a single direction (for the three-way interaction on judgments of avoidance, $d=0.72$ ). Thus the data are suggestive, though they do not conclusively support the directional prediction described above. The absolute values of the standardized $d$ 's for the remaining impressions ranged from 0.15 to 0.51 . One way to summarize these analyses is that in all cases, the cell that elicited the most extreme negative judgment was when targets were suppressing amusement that the participant expected them to show.

Mediation analyses. We hypothesized that the main effect of suppression on participants' interest in affiliating with the suppressors would be mediated by the personality judgments. Because of potential overlap between the interpersonal motive items (for avoidance and anxiety) and items for interest in affiliating, we limited our analyses to judgments of trait extraversion and agreeableness. We conducted a bootstrap mediation analysis testing extraversion and agreeableness as simultaneous mediators. As reported earlier, the total effect of suppression on interest in affiliating was $D=-16.81$. The mediation analysis decomposed this total effect into three components: an indirect effect mediated by extraversion judgments, an 
indirect effect mediated by agreeableness judgments, and a direct (unmediated) effect. The analysis indicated that all three components contributed to the total effect. The indirect effect via extraversion was $D=-6.30,95 \%$ CI $[-10.21,-2.83], d=-0.28$, and the indirect effect via agreeableness was $D=-3.62,95 \%$ CI $[-5.60,-1.96], d=-0.21$, consistent with the conclusion that the effect was doubly mediated by trait judgments of extraversion and agreeableness. The direct effect of suppression was $D=-6.89,95 \%$ CI $[-10.96,-2.82], d=-0.37$. Thus the evidence was consistent with partial mediation, about $59 \%$ of the total effect.

\section{Discussion}

Suppressors were judged to be less extraverted, less agreeable, and more avoidant and anxious of close relationships than targets who were reacting naturally to an emotion-eliciting stimulus. These effects did not appear to be solely a result of suppressors appearing unfeeling. All of the effects of suppression were amplified when targets suppressed amusement compared to sadness, and the personality trait judgments (i.e., extraversion and agreeableness) were amplified when participants had context information about the emotion-eliciting event that the targets were reacting to compared to when they did not. Finally, the negative trait judgments that participants formed of the suppressors' personalities partially explained why they were less interested in affiliating with the suppressors.

Extraversion and agreeableness are both broad factors that encompass many more specific aspects and facets (Saucier \& Srivastava, in press). With factor-level measurement of personality trait judgments, it is not possible to tell what specific aspects or facets are driving these judgments. For example, the extraversion findings could indicate that suppressors are viewed as less gregarious and enthusiastic, or that they are viewed as less assertive (or both). The agreeableness findings could indicate that suppressors are viewed as less warm and 
compassionate, or that they are viewed as less polite and proper (or both). To give a finer-grained view of personality trait judgments, in Study 2 we measured judgments of Big Five aspects (DeYoung, Quilty, \& Peterson, 2007) in addition to replicating our measurements of factor-level judgments.

Another issue we wanted to further examine in Study 2 was how participants were interpreting the suppressors' emotional expression (or lack thereof) in comparison to the expressers. In Study 1, suppression had direct effects on judgments of personality traits, interpersonal motivation, and interest in affiliating even when accounting for judgments of emotional experience, suggesting that perceivers were not merely responding to the suppressors appearing unfeeling. Although experience and expression often go together, in Study 2 we added items about emotional expression, allowing us to more explicitly examine whether suppressors appeared inexpressive. Similar to Study 1, we also looked at whether there were still appreciable direct effects of suppression on judgments of personality traits, interpersonal motivation, and interest in affiliating even when judgments of experience and expression were included in the analyses.

In addition to measuring judgments of emotional expression, we added a condition where perceivers saw a target who was viewing an emotionally neutral film clip. We used this condition to compare two possible interpretations of how perceivers use expressive behavior. One possibility is that perceivers may simply respond to a quantitative continuum of expressive behavior, from none to a little to a lot. If so, then when suppressors leak small amounts of expressive behavior they would look like they are mildly amused or mildly sad - in other words, just a less intense version of an ordinary expression. According to this explanation, there is nothing special about suppression from a perceiver's perspective - it is just on a continuum of 
expressivity. However, a second possibility is that suppression may be interpreted as

qualitatively different from expression. This may be because perceivers judge the small amounts of leaked expressive behavior as distinct from true expressions, or because there are distinct facial behaviors that are special to suppression (Gross \& Levenson, 1993, 1997). These two possibilities lead to two different predictions in the data. If the continuum hypothesis is correct and suppression is just viewed as low-intensity expression, then judgments of the suppress targets should be intermediate between the neutral and express targets. But if suppression is viewed as qualitatively different than low-intensity expression, then suppressors should be judged more negatively than either neutral or express targets.

\section{Study 2}

Replicating Study 1, we hypothesized that suppressors would be judged as less extraverted, less agreeable, and more avoidant in close relationships than expressers. Also replicating Study 1, we hypothesized that participants would be less interested in affiliating with suppressors compared to expressers, and that trait judgments of extraversion and agreeableness would mediate this effect. We included the same measures of extraversion and agreeableness that were in Study 1, but to further probe the effect of suppression on the trait judgments we added measures of two aspects of extraversion (enthusiasm and assertiveness) and two aspects of agreeableness (compassion and politeness). We also added a $5^{\text {th }}$ within-subject condition with a neutral target, which allowed us to test whether suppression had effects that were distinct from simply being on a quantitative continuum of expressivity (by seeing if judgments of suppressors fall between judgments of neutral targets and expressers).

\section{Method}


Participants and procedure. Participants were $N=238$ undergraduates $(66 \%$ female; Mage $=23$ years) from a large university in the northwestern United States. The sample size was based on a plan to run at least 200 subjects, and then continue data collection until the end of the academic term in which the study took place. We chose a larger goal $N$ because effect sizes sometimes decline in replications (Schooler, 2011). No data were analyzed until data collection was complete. Once again, the ethnic composition reflected that of the general student population at the university: 3\% American Indian/Alaska Native, 9\% Asian, 4\% Native Hawaiian or Other Pacific Islander, 3\% Black or African American, 74\% White, and 8\% other (participants were allowed to mark more than one category). In exchange for their participation, participants received credit in partial fulfillment of a course requirement. This study was approved by the authors' institutional review board.

The procedure was the same as Study 1 with two extensions. First, in addition to watching the four videos described in Study 1 (express amusement, express sadness, suppress amusement, and suppress sadness), each participant watched a neutral video where the target gave his or her natural reaction to a neutral film clip (a screensaver). As in Study 1, participants viewed these five videos in either the no-context $(n=115)$ or context condition $(n=123)$, which varied between subjects. Target person and serial position were again counterbalanced. After watching each video, participants reported their judgments of the target's emotional experience and expression, personality judgments of the target, and interest in affiliating with the target. The second extension was the addition of items to measure aspects of extraversion and agreeableness. The entire procedure took about one hour to complete.

Measures. As in Study 1, we asked participants how much they thought each target was experiencing amusement and sadness during the video. For Study 2 we also asked how much the 
target was expressing amusement and sadness. Each of these was measured with a single item.

As in Study 1, these items were mixed with other emotion items as fillers to disguise our interest in amusement and sadness.

Also as in Study 1, we measured personality judgments of the targets with the BFI-10 and the shortened ECR, and we also measured participants' interest in affiliating with the targets with the five interest in affiliating items. On the BFI-10, alphas for extraversion ranged from .34 to .73 across the five within-subject conditions; agreeableness from .53 to .66 ; conscientiousness from .48 to .68 ; neuroticism from .36 to .63 ; and openness to experience from .32 to .52 . On the shortened ECR, alphas for avoidant attachment ranged from .70 to .82; and anxious attachment from .73 to .86 . For interest in affiliating with the targets, alphas ranged from .95 to .96 .

We also measured judgments of two more specific aspects of extraversion, enthusiasm and assertiveness, and two aspects of agreeableness, compassion and politeness. These judgments were measured with items from the Big Five Aspect Scales (BFAS; DeYoung et al., 2007). The original BFAS scales each have 10 items that were selected for self-reports of personality. We wanted briefer scales to avoid burdening participants, and not all of the items were appropriate for rating a stranger. We therefore created shorter scales by selecting five items per aspect that fit the needs of the study, rewording them to the third person when necessary. Example items are: for enthusiasm, "Makes friends easily;" for assertiveness, "Sees himself/herself as a good leader;" for compassion, "Sympathizes with others' feelings;" and for politeness, "Avoids imposing his/her will on others." Each aspect was measured on a scale from 1 (disagree strongly) to 5 (agree strongly). Alphas for enthusiasm ranged from .82 to .88; for assertiveness, from .70 to .77; for compassion, from .73 to .83; and for politeness, from .65 to .74 . 


\section{Results}

Judgments of emotional experience and expression. Means and standard deviations of participants' judgments of the targets' emotion experience and expression are shown in Supplement 2. The effect of the suppression manipulation on ratings of the targets' emotion experience was replicated. Targets suppressing amusement were judged to be feeling less amusement than targets expressing amusement (no-context condition, $D=-49.47[-53.99$, 44.94], $d=-2.14$; context condition, $D=-39.19[-44.10,-34.28], d=-1.63)$, and targets suppressing sadness were judged to be feeling less sadness than targets expressing sadness (nocontext condition, $D=-21.79[-27.28,-16.30], d=-0.72$; context condition, $D=-23.14[-28.73$, 17.55], $d=-0.82)$.

We found similar results for judgments of the targets' emotion expression. Targets suppressing amusement were judged to be showing less amusement than targets expressing amusement regardless of context condition (no-context condition, $D=-49.81[-54.14,-45.49], d$ $=-2.04$; context condition, $D=-45.33[-50.48,-40.18], d=-1.79)$, and targets suppressing sadness were judged to be showing less sadness than targets expressing sadness regardless of context condition (no-context condition, $D=-22.05[-27.85,-16.26], d=-0.72$; context condition, $D=-26.17[-31.72,-20.61], d=-0.86)$. All of these were large effects by conventional benchmarks.

The above analyses (and the analyses in Study 1) indicated that suppressors appeared to be feeling and showing less emotion than expressers. But that was only a relative difference; did suppressors appear completely unfeeling or inexpressive? To test this in Study 2, we compared participants' ratings of the emotions experienced and expressed by the suppress targets versus the neutral targets. The results indicated that the participants did indeed perceive signs of 
emotion in the suppress targets. Relative to the neutral targets and regardless of context condition, the suppress-amuse targets were judged to be feeling more amusement (no-context condition: $D=9.35,95 \%$ CI $[4.27,14.43], d=0.28$; context condition: $D=22.88[17.06,28.69]$, $d=0.84$ ) and showing more amusement (no-context condition: $D=7.81,95 \%$ CI $[2.48,13.14]$, $d=0.23$; context condition: $D=14.89[9.38,20.40], d=0.52)$. When comparing the suppresssad targets to the neutral targets, the difference in participants' ratings of the experience of sadness was small and equivocal in the no-context condition, $D=2.81,95 \% \mathrm{CI}[-1.66,7.28], d=$ 0.12. In the context condition however, suppress-sad targets were judged as feeling more sad than the neutral targets, $D=38.13[33.36,42.90], d=2.11$. Finally, regardless of context condition, the suppress-sad targets were judged to be showing more sadness than the neutral targets (no-context condition: $D=5.24,95 \% \mathrm{CI}[0.33,10.16], d=0.24$; context condition: $D=$ $31.04[25.84,36.25], d=1.66)$. Thus, the evidence was not consistent with a hypothesis that the suppress targets appeared completely unfeeling or inexpressive. Suppressors were judged to be feeling and showing substantially less emotion than the expressers, but a little more than the neutral targets.

\section{Main effects of suppression on personality judgments and affiliation. Means and} standard deviations across all of the conditions are reported in Table 2. The main effects of suppression on the Big Five personality traits replicated the results of Study 1. Suppressors were judged as less extraverted, $D=-31.34,95 \%$ CI $[-33.88,-28.80], d=-1.49$; and less agreeable, $D$ $=-10.63,95 \% \mathrm{CI}[-12.86,-8.41], d=-0.59$. To better understand the effects of suppression on trait judgments of extraversion and agreeableness, we also examined the two aspects of each. On the extraversion aspects, suppressors were judged to be less enthusiastic, $D=-24.89$, 95\% CI [27.17, -22.61], $d=-1.32$; and less assertive, $D=-13.08,95 \% \mathrm{CI}[-15.34,-10.81], d=-0.81$. On 
the agreeableness aspects, suppressors were judged as less compassionate, $D=-18.44,95 \% \mathrm{CI}$ [$20.80,-16.07], d=-1.03$, but the main effect of suppression on judgments of politeness was weak and equivocal, $D=-1.03,95 \%$ CI $[-2.75,0.69], d=-0.07$.

For the remaining Big Five personality traits, suppressors were judged to be less open to experience, $D=-11.85,95 \%$ CI $[-13.87,-9.83], d=-0.71$; and less conscientious, $D=-5.43$, 95\% CI [-7.48, -3.37], $d=-0.32$. Suppressors and expressers did not differ in judgments of neuroticism, $D=0.04,95 \% \mathrm{CI}[-2.38,2.45], d=0.003$.

The main effects of suppression on the interpersonal motivation judgments also replicated the results of Study 1. Suppressors were seen as more avoidant in close relationships, $D=21.83,95 \%$ CI $[19.63,24.03], d=1.32$; and more anxious in close relationships, $D=4.88$, $95 \%$ CI $[2.85,6.91], d=0.30$.

Replicating Study 1, participants were less interested in affiliating with the suppressers compared to the expressers, $D=-16.51,95 \%$ CI $[-19.22,-13.80], d=-0.78$. As shown in Table 2, this effect held across both emotions and both context conditions.

As in Study 1, we ran mediated simple effects analyses (separated by the emotion conditions, with corresponding emotion judgments). This time we included mediated paths via perceived emotion experience and perceived emotion expression, as well as direct effects of suppression. We ran these analyses for judgments of extraversion, agreeableness, all four aspects, avoidance, anxiety, and interest in affiliating; full results are reported in Supplement 3. Even after including mediating paths via emotion experience and expression judgments in the model, suppression continued to have substantial and reliable direct effects on judgments of extraversion, agreeableness, enthusiasm, compassion, avoidance, and interest in affiliating. 
Interactions with emotion. Study 1 found that for judgments of extraversion, agreeableness, and both types of insecure attachment in close relationships, the effect of suppression (vs. expression) was stronger when targets were suppressing amusement than when they were suppressing sadness. We found very similar results in Study 2: for extraversion, $D=-$ 14.89, 95\% CI [-19.27, -10.51$], d=-0.73$; for agreeableness, $D=-3.65,95 \% \mathrm{CI}[-7.75,0.44], d$ $=-0.21$ (note however that the point estimate of this effect is small and the confidence interval is consistent with an effect of zero); for avoidant attachment, $D=7.23,95 \% \mathrm{CI}[4.10,10.36], d=$ 0.46 ; and for anxious attachment, $D=11.50,95 \%$ CI $[8.11,14.88], d=0.72$.

For the aspects of extraversion and agreeableness, the effect of suppression was greater for amusement than sadness for both aspects of extraversion (see Figure 4): for enthusiasm, $D=$ $11.19,95 \% \mathrm{CI}[-14.79,-7.58], d=-0.62$; and for assertiveness, $D=-5.01,95 \% \mathrm{CI}[-8.44,-1.58]$, $d=-0.32$. For the aspects of agreeableness, the effect estimates were small and the confidence intervals were consistent with zero or weak effects in either direction; for compassion, $D=2.21$, $95 \%$ CI $[-1.24,5.67], d=0.11$; and for politeness, $D=0.94,95 \%$ CI $[-2.14,4.02], d=0.07$.

Finally, consistent with Study 1, the effect of suppression on participants' interest in affiliating with the targets was greater for amusement than for sadness, $D=-5.48,95 \% \mathrm{CI}[-9.52$, $-1.43], d=-0.28$.

Interactions with context cues. Study 1 found that for judgments of extraversion and agreeableness, the effects of suppression were stronger when participants had context cues than when they did not. In Study 2, we again found a suppression-by-context interaction for judgments of extraversion, $D=-6.52,95 \% \mathrm{CI}[-11.61,-1.44], d=-0.31$. This interaction was also apparent for both aspects of extraversion (see Figure 5): for enthusiasm, $D=-5.21,95 \% \mathrm{CI}$ $[-9.77,-0.65], d=-0.27$; and for assertiveness, $D=-4.86,95 \%$ CI $[-9.39,-0.33], d=-0.30$. 
However, evidence for an interaction on judgments of agreeableness was weak and equivocal, $D=-0.86,95 \% \mathrm{CI}[-5.32,3.59], d=-0.04$. This was also the case for both aspects of agreeableness: for compassion, $D=-3.13,95 \% \mathrm{CI}[-7.85,1.60], d=-0.15$; and for politeness, $D$ $=-0.04,95 \%$ CI $[-3.48,3.40], d=0.01$.

As in Study 1, there was no clear evidence for interactions with context on judgments of avoidance and anxiety: for avoidance, $D=3.37,95 \%$ CI $[-1.03,7.76], d=0.19$; and for anxiety, $D=2.73,95 \%$ CI $[-1.33,6.80], d=0.18$.

Study 1 found that the effect of suppression on interest in affiliating was greater in the context condition compared to the no-context condition. In Study 2 however, evidence of this interaction was weaker and more equivocal, $D=-1.52,95 \%$ CI $[-6.94,3.90], d=-0.07$.

Three-way interactions. Like in Study 1, we examined the three-way interactions in an exploratory step and summarize the results here. For most of the impressions examined in Study 2, the suppression-by-emotion interaction differed between the no-context condition and the context condition, similar to Study 1. The confidence intervals of the three-way interactions were exclusively in the predicted direction for judgments of extraversion $(d=-0.49)$ and both the enthusiasm $(d=-0.35)$ and assertiveness $(d=-0.50)$ aspects of extraversion. The three-way interaction effect for the other impressions were mostly in a similar direction but the intervals included effects in either direction (the absolute values of the standardized $d$ 's ranged from 0.003 to 0.38 ). A noteworthy deviation from this pattern was for judgments of politeness, where the three-way interaction was in the opposite direction of the others and the effect of suppression was greater for sadness than for amusement in the context condition $(d=0.49)$. One way of characterizing this result is that when participants were able to see the emotion-eliciting film 
clip, they did not judge targets who suppressed amusement as less polite than targets who expressed amusement. We return to this finding in the general discussion.

\section{Comparing suppress and neutral targets: Is suppression judged as weak}

expression? As reported earlier, analyses revealed that the suppress targets were judged to be expressing and (in most conditions) experiencing more emotion than the neutral targets, but less than the fully-expressing targets. How did this affect personality judgments? Here we report analyses probing whether the suppress targets were judged as intermediate on an expressivity continuum (i.e., whether judgments of suppressors' personalities fell between judgments of neutral targets and expressers), or whether suppressors were judged as qualitatively different.

First we compare targets who viewed the sad film clip to those who viewed the neutral film clip. The data largely contradicted the continuum hypothesis in both the no-context and context conditions (see top half of Table 3). Compared to neutral targets, suppress-sad targets were viewed as less extraverted, enthusiastic, assertive, agreeable, compassionate, and more avoidant, and participants were less interested in affiliating with the suppressors; all of these differences were the opposite of what the continuum hypothesis would predict (see means and standard deviations in Table 2). This was true in both the no-context and context conditions, though it was stronger in the context condition. However, results for politeness and anxiety were consistent with the continuum hypothesis: for these dimensions, judgments of suppressors were between judgments of neutral targets and expressers.

When we compared targets viewing the amusing film clip to those viewing the neutral film clip, the data largely contradicted the continuum hypothesis in the context condition (see bottom half of Table 3). When participants saw the emotion-eliciting context, suppress-amuse targets were judged as less extraverted, enthusiastic, assertive, compassionate, and polite, and 
more avoidant and anxious than the neutral targets; participants were also less interested in affiliating with the suppressors. For agreeableness, suppress-amuse and neutral targets were viewed as nearly identical on average. However, in the no-context condition the continuum hypothesis was not clearly rejected. For the most part, impressions of the suppress-amuse targets were either little different from the neutral target or slightly more favorable than the neutral target (the latter being consistent with the continuum hypothesis).

Mediation analyses. In Study 1 we found that personality trait judgments of extraversion and agreeableness statistically mediated the effect of suppression on participants' interest in affiliating with the suppressors. In Study 2, we replicated this analysis. In addition, we conducted an analysis in which we entered the four aspects of extraversion and agreeableness as mediators, in order to see whether particular aspects were driving the effect.

Recall that the total effect of suppression on interest in affiliation was $D=-16.51$. Replicating the findings from Study 1, the effect was mediated by personality trait judgments of extraversion and agreeableness. The indirect effect of extraversion was $D=-8.61,95 \%$ CI [$12.58,-4.80], d=-0.40$, and the indirect effect of agreeableness was $D=-4.65,95 \%$ CI $[-6.43,-$ 2.83], $d=-0.25$. However, unlike Study 1, the direct effect of suppression was reduced close to zero, consistent with full mediation: $D=-3.25,95 \%$ CI $[-7.79,1.29], d=-0.15$.

When we modeled the four trait aspects as mediators instead of the two trait factors, the results revealed that enthusiasm (an aspect of extraversion) and compassion (an aspect of agreeableness) were substantial mediators: the indirect effect of enthusiasm was $D=-7.79,95 \%$ CI $[-11.57,-4.33], d=-0.41$, and the indirect effect of compassion was $D=-4.73,95 \%$ CI $[-8.75$, $-0.99], d=-0.26$. By comparison, the indirect effects of assertiveness (an aspect of extraversion) and politeness (an aspect of agreeableness) were weak and not reliably in either direction: for 
assertiveness, $D=-2.30,95 \% \mathrm{CI}[-5.05,0.48], d=-0.14$; and for politeness, $D=-2.98,95 \% \mathrm{CI}$ $[-6.82,1.08], d=-0.20$. In the model with the four aspects as mediators, there was again evidence of full mediation: the direct effect of suppression was reduced close to zero, $D=0.55$, $95 \%$ CI $[-3.29,4.38], d=0.03 .{ }^{1}$ In other words, it appears that participants are less interested in affiliating with suppressors primarily because suppressors are judged to be less enthusiastic and less compassionate.

\section{Joint Analyses of Replicability of Effects}

Study 2 contained a complete replication of Study 1 (in addition to extending it in several ways). In order to evaluate the replicability of the findings, we conducted a series of joint analyses of both datasets together. The joint analyses had two goals. First, we wanted to determine whether the effects found in Study 2 were similar or different from those found in Study 1; substantial differences could be interpreted as a "failure to replicate." Second, if the results were not substantially different, we wanted to obtain more precise effect estimates from the combined dataset.

In order to evaluate whether results from the two studies were substantially different, we ran all analyses in the combined dataset with study (Study 1 vs. Study 2 ) included as a moderator variable. This was to indicate how the effects differed by study. For example, a suppression-bystudy interaction would indicate how much the main effect of suppression differed by study; a suppression-by-emotion-by-study interaction would indicate how much the suppression-byemotion interaction differed by study; etc. Of 23 effects examined (see Supplement 5), the differences were generally small. In only two cases were the data inconsistent with the hypothesis that the effects were replicated across studies (i.e., $95 \%$ confidence intervals of effects excluded zero): the main effects of suppression on judgments of extraversion and 
avoidance were larger in Study 2 than in Study 1. However, both effects were in the same direction in both studies, and across so many analyses some differences would be expected by chance. We therefore concluded that Study 2 was a "successful" replication of Study 1.

Table 4 contains the effect estimates from the joint analyses, combining data from both studies. These numbers represent our best (i.e., most precise) estimates of the effects that were investigated in both studies. The joint analyses show robust evidence that suppression affects a variety of judgments of personality traits and interpersonal motivations, and that these effects were stronger for amusement and stronger when perceivers knew the emotion-eliciting context.

\section{General Discussion}

How does suppression affect personality judgments? In two studies, we found that perceivers who saw targets suppressing their emotional expressions (versus reacting spontaneously) while watching amusing and sad film clips judged the suppressors to be less extraverted, less agreeable, and more insecure about relationships, and that (perhaps as a consequence) perceivers were less interested in affiliating with the suppressors compared to the expressers. The aspects of extraversion and agreeableness that suppressors were judged especially low on were enthusiasm and compassion. It therefore appears that suppression is interpreted by others as a signal that one is not interested in socializing and not a caring person. Moreover, personality judgments of suppressors (relative to expressers) were amplified under two circumstances: (1) when the emotion being suppressed was amusement (compared to sadness) and (2) when perceivers had cues about the emotion-eliciting context (compared to when they did not). We discuss some of the further implications of these findings.

\section{A Complement to the Relationship Dynamics Account}


Suppressors have relationships that are less close, less supportive, and less satisfying; and prospective longitudinal evidence is consistent with suppression being an antecedent of relationship problems (English, John, Srivastava, \& Gross, 2012; Srivastava et al., 2009). Previous research on the social consequences of suppression has tended to focus on how suppression disrupts the reciprocal dynamics present in social interactions and existing relationships (Butler et al., 2003; English \& John, 2013; Impett et al., 2012). The present study complements this view, showing that suppression can sour the impressions that potential relationship partners form of suppressors, even when they have never met. Thus, while there is robust support for the relationship dynamics account, the present study shows that disrupted relationship dynamics are not the only reason why suppressors experience negative social consequences.

Considering the two mechanisms together suggests that there may be a twofold blow of habitual suppression: people who suppress their emotions will have a harder time forming close and affiliative relationships in the first place, and the relationships that they do form may be more strained. For people who habitually use suppression, interventions or other efforts to overcome these negative consequences may need to be both early and sustained.

\section{What Does Suppression Signal?}

We found that suppressors were judged as feeling and showing less emotion than expressers, but more than neutral targets. However, the analyses examining the mediating role of perceived emotional experience and expression, and the inclusion in Study 2 of an additional condition with a neutral target, provided converging evidence that suppression was not interpreted simply as lower-intensity emotional expression; there may be something particular about suppression. For sadness, the perceivers judged suppressing targets more harshly than 
neutral targets, and this was true even in the no-context condition. This suggests that either perceivers can pick up on something in the facial behavior of people suppressing sadness (as suggested by Gross \& Levenson, 1997), or that perceivers do not make a monotonic mapping of no, low, and high amounts of emotion-expressive behavior onto personality judgments and decisions about affiliation. For amusement, on the other hand, the continuum hypothesis was only rejected when perceivers saw the emotion-eliciting event, suggesting that perceivers might be relying on context cues to distinguish suppression from weak expression of amusement.

These findings can be interpreted in light of social-functional accounts of emotion, which emphasize that emotions are interpersonal phenomena (Fischer \& Manstead, 2008; Keltner \& Haidt, 1999). Emotional expressions signal intentions and other mental states to others and allow for the rapid and ongoing coordination of social interactions (Keltner \& Kring, 1998). This facilitates a wide range of social processes, including the maintenance of close relationships (Carstensen, Gottman, \& Levenson, 1995), alleviating distress (Kennedy-Moore \& Watson, 2001), and status conferral (Tiedens, 2001).

What happens, then, when someone suppresses their emotion-expressive behavior? Relationships require an investment of time and making oneself emotionally vulnerable. People therefore do not pursue close relationships indiscriminately - they probably look for people who are likely to reciprocate their investments. So when perceivers detect that someone is hiding their emotions, they may interpret that as a disinterest in the things that emotional expression facilitates - closeness, social support, and interpersonal coordination. Perceivers' own motivations, including their interest in affiliating, may in turn be affected by these judgments, as suggested by the mediation analyses.

\section{The Importance of Expectations, Both Proximal and Distal}


We found that suppression affected personality judgments even in the no-context condition, suggesting that perceivers were able to form negative impressions of suppressors from their nonverbal behavior. This suggests that extensive contextual information is not necessary for perceivers to draw personality inferences of suppressors. However, when we provided perceivers with contextual information to help them interpret suppressors' behavior, the effects of suppression were magnified. Thus, when context information was available the perceivers used it.

This finding has implications beyond just the fact that context helps perceivers detect suppression. If perceivers are using context cues to form expectations about emotional expression (Burgoon, 1993), they may also form expectations about whether suppression is an appropriate response. In the present study targets were watching emotion-eliciting film clips. These clips have been pre-tested to elicit amusement or sadness from a wide range of people (Rottenberg et al., 2007), so it is probably safe to assume that the perceivers in the context condition (who saw the clips) would have recognized them as normatively funny or sad. Thus, the perceivers might have expected that a "normal" person would be expressing the congruent emotional response and judged suppressors negatively based on that expectation. However, our data contained one indication (admittedly one we did not anticipate) that suppression can lead to more favorable judgments too. The amusing film clip was a movie scene in which a woman pretends to have an orgasm in a crowded restaurant in order to embarrass her date. In Study 2, perceivers in the context condition (who saw the film clip that the targets were viewing) rated the suppressors as slightly higher in politeness compared to the expressers. This may have been because of the racy content of the film clip. In future research, it would be valuable to follow up on this possibility by studying personality judgments of people in emotion-eliciting situations 
where suppression might be viewed as a normative or socially appropriate response. Perhaps under those circumstances suppressors would be viewed more favorably than expressers, not less.

Why does suppressing amusement have greater negative consequences than suppressing sadness? One possible reason has to do with cultural display rules in Western cultures (Matsumoto et al., 2008). Because the expression of positive emotion is more appropriate than the expression of negative emotion, suppressing a positive emotion such as amusement runs counter to expectations for what emotions someone should show, more so than suppressing a negative emotion such as sadness. Another, related reason is that the suppression of amusement is less common than the suppression of sadness in daily life (Gross et al., 2006). As a result, suppressing amusement may have greater negative consequences solely because it is more salient. Thus, a plausible interpretation of the emotion moderator effects is that they were related to a more distal set of expectations - expectations based on perceivers' cultural backgrounds and everyday experience.

\section{Limitations and Future Directions}

Our investigation was motivated by past research showing that suppressors have difficulties with close relationships. We replicated the previous finding that others do not want to affiliate with suppressors, and we presented statistical evidence that this effect is mediated by personality trait judgments. We similarly examined perceived emotion experience and expression as mediators of the effects of suppression on personality judgments. Although such measurement-of-mediation designs are preferred when it is easy to measure the hypothesized mediator yet difficult to manipulate it, this design is not without limitations (Bullock, Green, \& Ha, 2010; Spencer, Zanna, \& Fong, 2005). As a result of not manipulating the mediator, the 
relationship between the mediator (personality trait judgments of suppressors) and the dependent variable (perceivers' disinterest in affiliating with suppressors) could be due to some unmeasured third variable, such as the perceivers' mood while watching the videos of the suppressors. Further, the causal direction underlying this relationship remains unclear: Do perceivers' unfavorable personality trait judgments of suppressors cause them to be less interested in affiliating with suppressors or do perceivers' decreased interest in affiliating with suppressors cause them to form unfavorable personality trait judgments of suppressors? Evidence for mediation requires a programmatic, multi-method investigation (Bullock et al., 2010); the statistical tests presented in this paper should be viewed as suggestive evidence but not conclusive. Future research that includes experimental manipulations of hypothesized mediators can clarify their role.

To test our account for why suppression is socially costly, we had perceivers watch videos of targets suppressing their emotion to amusing and sad film clips. This design was useful for inferring causality and controlling extraneous factors. For example, spontaneous habitual suppression in daily life is correlated with a number of other individual differences (Gross \& John, 2003); therefore, by having the same target persons appear in all conditions, we could rule out any potential confounding of suppression with other target characteristics. The design also allowed us to conduct a more controlled test of a finding that has come from naturalistic studies, that suppression reduces others' interest in affiliating (Butler et al., 2003; Srivastava et al., 2009), providing further multi-method support for that conclusion. However, the use of prepared videos limited the external and ecological validity of these experiments. Just as the present study built on past naturalistic research by taking it into the lab, future work can build on the current study by employing more naturalistic zero-acquaintance designs, such as having perceivers watch 
suppressors and non-suppressors in unscripted social interactions. Such research might further benefit from studying clinical populations with known differences in emotional functioning, such as people with alexithymia. Although such an approach would sacrifice some experimental control, it would complement the present investigation by evaluating whether uninstructed, naturally-occurring suppression has qualitatively similar effects, it would allow analysis of suppression cues within a representative design (Brunswik, 1956), and it would help address whether the effect sizes obtained here under controlled laboratory conditions are of similar magnitude in naturalistic interactions.

Another limitation is that we only examined two emotions, amusement and sadness. We chose these two emotions as a starting point because they are two of the most common emotions suppressed in everyday life (Gross et al., 2006) and they represented a contrast of one positive emotion with one negative one. With just these two emotions we were able to show that the effects of suppression on others' impressions are different for different emotions. However it is possible that judgments of people who suppress other emotions, such as surprise or fear, may be different still. Our general theoretical framework gives a starting point for generating predictions about other emotions: we would expect judgments of people who suppress other emotions to be based, in part, on whether suppression was viewed as normative or socially appropriate. Specific predictions would depend on the particular emotion being suppressed and on both the proximal situation and broader cultural context.

\section{Conclusion}

Our studies extend and add to research on the social consequences of suppression. People who suppress their emotions, especially amusement and especially when the normative response is to show it, are perceived less extraverted, less agreeable, and more insecure towards 
relationships. Further, the negative personality trait judgments that perceivers form of suppressors help to explain why suppressors experience difficulty forming close and meaningful relationships. This research complements previous work on relationship dynamics, by showing that expressive suppression also functions as a social signal that can prevent relationships from forming in the first place. And it showed that judgments of suppression are variable across emotions and across contexts. 


\section{References}

Albright, L., Kenny, D. A., \& Malloy, T. E. (1988). Consensus in personality judgments at zero acquaintance. Journal of Personality and Social Psychology, 55, 387-395. doi:10.1037/0022-3514.55.3.387

Ambady, N., Bernieri, F. J., \& Richeson, J. A. (2000). Toward a histology of social behavior: Judgmental accuracy from thin slices of the behavioral stream. In M. P. Zanna (Ed.), Advances in experimental social psychology (Vol. 32, pp. 201-271). San Diego, CA: Academic Press.

Ambady, N., Hallahan, M., \& Rosenthal, R. (1995). On judging and being judged accurately in zero-acquaintance situations. Journal of Personality and Social Psychology, 69, 518-529. doi:10.1037/0022-3514.69.3.518

Ames, D. R., \& Bianchi, E. C. (2008). The agreeableness asymmetry in first impressions: Perceivers' impulse to (mis)judge agreeableness and how it is moderated by power. Personality and Social Psychology Bulletin, 34, 1719-1736. doi:10.1177/0146167208323932

Arya, A., Jefferies, L. N., Enns, J. T., \& DiPaola, S. (2006). Facial actions as visual cues for personality. Computer Animation and Virtual Worlds, 17, 371-382. doi:10.1002/cav.140

Borkenau, P., Brecke, S., Möttig, C., \& Paelecke, M. (2009). Extraversion is accurately perceived after a 50-ms exposure to a face. Journal of Research in Personality, 43, 703706. doi:10.1016/j.jrp.2009.03.007

Borkenau, P., \& Liebler, A. (1992). Trait inferences: Sources of validity at zero acquaintance. Journal of Personality and Social Psychology, 62, 645-657. doi:10.1037/0022-3514.62.4.645

Borkenau, P., Mauer, N., Riemann, R., Spinath, F. M., \& Angleitner, A. (2004). Thin slices of 
behavior as cues of personality and intelligence. Journal of Personality and Social Psychology, 86, 599-614. doi:10.1037/0022-3514.86.4.599

Brennan, K. A., Clark, C. L., \& Shaver, P. R. (1998). Self-report measurement of adult attachment: An integrative overview. In J. A. Simpson \& W. S. Rholes (Eds.), Attachment theory and close relationships (pp. 46-76). New York, NY: Guilford Press.

Brown, W. M., \& Moore, C. (2002). Smile asymmetries and reputation as reliable indicators of likelihood to cooperate: An evolutionary analysis. In S. P. Shohov (Ed.), Advances in psychology research (Vol. 11, pp. 59-78). Huntington, NY: Nova Science Publishers.

Brunswik, E. (1956). Perception and the Representative Design of Psychological Experiments. Berkeley: University of California Press.

Bullock, J. G., Green, D. P., \& Ha, S. E. (2010). Yes, but what's the mechanism? (don’t expect an easy answer). Journal of Personality and Social Psychology, 98, 550-558. doi:10.1037/a0018933

Burgoon, J. K. (1993). Interpersonal expectations, expectancy violations, and emotional communication. Journal of Language and Social Psychology, 12, 30-48. doi:10.1177/0261927X93121003

Butler, E. A., Egloff, B., Wilhelm, F. H., Smith, N. C., Erickson, E. A., \& Gross, J. J. (2003). The social consequences of expressive suppression. Emotion, 3, 48-67. doi:10.1037/1528-3542.3.1.48

Butler, E. A., Lee, T. L., \& Gross, J. J. (2007). Emotion regulation and culture: Are the social consequences of emotion suppression culture-specific? Emotion, 7, 30-48. doi:10.1037/1528-3542.7.1.30

Carney, D. R., Colvin, C. R., \& Hall, J. A. (2007). A thin slice perspective on the accuracy of 
first impressions. Journal of Research in Personality, 41, 1054-1072. doi:10.1016/j.jrp.2007.01.004

Carstensen, L. L., Gottman, J. M., \& Levenson, R. W. (1995). Emotional behavior in long-term marriage. Psychology and Aging, 10, 140-149. doi:10.1037/0882-7974.10.1.140

Cohen, J. (1992). A power primer. Psychological Bulletin, 112, 155-159. doi:10.1037/0033-2909.112.1.155

Cohen, P., Cohen, J., Aiken, L. S., \& West, S. G. (1999). The problem of units and the circumstance for POMP. Multivariate Behavioral Research, 34, 315-346. doi:10.1207/S15327906MBR3403_2

Cumming, G. (2012). Understanding the new statistics: Effect sizes, confidence intervals, and meta-analysis. New York, NY: Routledge.

Denissen, J. J. A., \& Penke, L. (2008). Motivational individual reaction norms underlying the Five-Factor model of personality: First steps towards a theory-based conceptual framework. Journal of Research in Personality, 42, 1285-1302. doi:10.1016/j.jrp.2008.04.002

DeYoung, C. G., Quilty, L. C., \& Peterson, J. B. (2007). Between facets and domains: 10 aspects of the Big Five. Journal of Personality and Social Psychology, 93, 880-896. doi:10.1037/0022-3514.93.5.880

Eisenberg, N., Fabes, R. A., Schaller, M., \& Miller, P. A. (1989). Sympathy and personal distress: Development, gender differences, and interrelations of indexes. New Directions for Child Development, 44, 107-126. doi:10.1002/cd.23219894408

English, T., \& John, O. P. (2013). Understanding the social effects of emotion regulation: The 
mediating role of authenticity for individual differences in suppression. Emotion, 13, 314-329. doi:10.1037/a0029847

English, T., John, O. P., Srivastava, S., \& Gross, J. J. (2012). Emotion regulation and peer-rated social functioning: A 4-year longitudinal study. Journal of Research in Personality, 46, 780-784. doi:10.1016/j.jrp.2012.09.006

Fischer, A. H., \& Manstead, A. S. R. (2008). Social functions of emotion. In L. Lewis, J. M. Haviland-Jones, \& L. Feldman Barrett (Eds.), Handbook of emotions (3rd ed., pp. 456468). New York, NY: Guilford Press.

Fraley, R. C., \& Waller, N. G. (1998). Adult attachment patterns: A test of the typological model. In J. A. Simpson \& W. S. Rholes (Eds.), Attachment theory and close relationships (pp. 77-114). New York, NY: Guilford Press.

Gosling, S. (2008). Snoop: What your stuff says about you. New York, NY: Basic Books. Graziano, W. G., \& Eisenberg, N. (1997). Agreeableness: A dimension of personality. In R. Hogan, J. Johnson, \& S. Briggs (Eds.), Handbook of personality psychology (pp. 795824). San Diego, CA: Academic Press.

Gross, J. J. (1998). Antecedent- and response-focused emotion regulation: Divergent consequences for experience, expression, and physiology. Journal of Personality and Social Psychology, 74, 224-237. doi:10.1037/0022-3514.74.1.224

Gross, J. J., \& John, O. P. (2003). Individual differences in two emotion regulation processes: Implications for affect, relationships, and well-being. Journal of Personality and Social Psychology, 85, 348-362. doi:10.1037/0022-3514.85.2.348

Gross, J. J., \& Levenson, R. W. (1993). Emotional suppression: Physiology, self-report, and expressive behavior. Journal of Personality and Social Psychology, 64, 970-986. doi:10.1037/0022-3514.64.6.970 
Gross, J. J., \& Levenson, R. W. (1995). Emotion elicitation using films. Cognition and Emotion, 9, 87-108. doi:10.1080/02699939508408966

Gross, J. J., \& Levenson, R. W. (1997). Hiding feelings: The acute effects of inhibiting negative and positive emotion. Journal of Abnormal Psychology, 106, 95-103. doi:10.1037/0021-843X.106.1.95

Gross, J. J., Richards, J. M., \& John, O. P. (2006). Emotion regulation in everyday life. In D. K. Snyder, J. A. Simpson, \& J. N. Hughes (Eds.), Emotion regulation in couples and families: Pathways to dysfunction and health (pp. 13-35). Washington, DC: American Psychological Association.

Hall, J. A., Gunnery, S. D., \& Andrzejewski, S. A. (2011). Nonverbal emotion displays, communication modality, and the judgment of personality. Journal of Research in Personality, 45, 77-83. doi:10.1016/j.jrp.2010.11.012

Heyman, G. D., \& Gelman, S. A. (1999). The use of trait labels in making psychological inferences. Child Development, 70, 604-619. doi:10.1111/1467-8624.00044

Impett, E. A., Kogan, A., English, T., John, O., Oveis, C., Gordon, A. M., \& Keltner, D. (2012). Suppression sours sacrifice: Emotional and relational costs of suppressing emotions in romantic relationships. Personality and Social Psychology Bulletin, 38, 707-720. doi:10.1177/0146167212437249

John, O. P., \& Soto, C. J. (2007). The importance of being valid: Reliability and the process of construct validation. In R. W. Robins, R. C. Fraley, \& R. F. Krueger (Eds.), Handbook of Research Methods in Personality Psychology (pp. 461-494). New York, NY: Guilford Press.

Judd, C. M., McClelland, G. H., \& Ryan, C. S. (2009). Data analysis: A model comparison 
approach (2nd ed.). New York, NY: Routledge.

Keltner, D., \& Haidt, J. (1999). Social functions of emotions at four levels of analysis. Cognition and Emotion, 13, 505-521. doi:10.1080/026999399379168

Keltner, D., \& Kring, A. M. (1998). Emotion, social function, and psychopathology. Review of General Psychology, 2, 320-342. doi:10.1037/1089-2680.2.3.320

Kennedy-Moore, E., \& Watson, J. C. (2001). How and when does emotional expression help? Review of General Psychology, 5, 187-212. doi:10.1037//1089-2680.5.3.187

Kenny, D. A., Horner, C., Kashy, D. A., Chu, L. (1992). Consensus at zero acquaintance: Replication, behavioral cues, and stability. Journal of Personality and Social Psychology, 62, 88-97. doi:10.1037/0022-3514.62.1.88

Knutson, B. (1996). Facial expressions of emotion influence interpersonal trait inferences. Journal of Nonverbal Behavior, 20, 165-182. doi:10.1007/BF02281954

Lakens, D. (2013). Calculating and reporting effect sizes to facilitate cumulative science: A practical primer for $t$-tests and ANOVAs. Frontiers in Psychology, 4, 1-12. doi:10.3389/fpsyg.2013.00863

Lin, N. (1986). Conceptualizing social support. In N. Lin, A. Dean, \& W. M Ensel (Eds.), Social support, life events, and depression (pp. 17-30). Orlando, FL: Academic Press.

Matsumoto, D., Yoo, S. H., Fontaine, J., Anguas-Wong, A. M., Arriola, M., Ataca, B., ... Grossi, E. (2008). Mapping expressive differences around the world: The relationship between emotional display rules and individualism versus collectivism. Journal of Cross-Cultural Psychology, 39, 55-74. doi:10.1177/0022022107311854

Morris, S. B., \& DeShon, R. P. (2002). Combining effect size estimates in meta-analysis with repeated measures and independent-groups designs. Psychological Methods, 7, 105-125. 
doi:10.1037//1082-989X.7.1.105

Morris, J. A., \& Feldman, D. C. (1996). The dimensions, antecedents, and consequences of emotional labor. Academy of Management Review, 21, 986-1010. doi:10.2307/259161

Pytlik Zillig, L. M., Hemenover, S. H., \& Dienstbier, R. A. (2002). What do we assess when we assess a Big 5 trait? A content analysis of the affective, behavioral, and cognitive processes represented in the Big 5 personality inventories. Personality and Social Psychology Bulletin, 28, 847-858. doi:10.1177/0146167202289013

Rammstedt, B., \& John, O. P. (2007). Measuring personality in one minute or less: A 10-item short version of the Big Five Inventory in English and German. Journal of Research in Personality, 41, 203-212. doi:10.1016/j.jrp.2006.02.001

Richards, J. M., Butler, E., \& Gross, J. J. (2003). Emotion regulation in romantic relationships: The cognitive consequences of concealing feelings. Journal of Social and Personal Relationships, 20, 599-620. doi:10.1177/02654075030205002

Rottenberg, J., Ray, R. D., \& Gross, J. J. (2007). Emotion elicitation using films. In J. A. Coan \& J. J. B. Allen (Eds.), Handbook of emotion elicitation and assessment (pp. 9-28). New York, NY: Oxford University Press, Inc.

Saucier, G., \& Srivastava, S. (in press). What are the most important dimensions of personality? A review and critique of studies of descriptors in diverse languages. In L. Cooper \& R. Larsen (Eds.), Handbook of social and personality psychology. Washington, DC: American Psychological Association.

Schmitt, N. (1996). Uses and abuses of coefficient alpha. Psychological Assessment, 8, 350-353. doi:10.1037/1040-3590.8.4.350

Schooler, J. (2011). Unpublished results hide the decline effect. Nature, 470, 437. 
doi:10.1038/470437a

Simpson, J. A., Gangestad, S. W., \& Nations, C. (1996). Sociosexuality and relationship initiation: An ethological perspective of nonverbal behavior. In G. J. O. Fletcher \& J. Fitness (Eds.), Knowledge structures in close relationships: A social psychological approach (pp. 121-146). Mahwah, NJ: Lawrence Erlbaum Associates, Inc.

Soto, J. A., Perez, C. R., Kim, Y., Lee, E. A., \& Minnick, M. R. (2011). Is expressive suppression always associated with poorer psychological functioning? A cross-cultural comparison between European Americans and Hong Kong Chinese. Emotion, 11, 14501455. doi:10.1037/a0023340

Spencer, S. J., Zanna, M. P., \& Fong, G. T. (2005). Establishing a causal chain: Why experiments are often more effective than mediational analyses in examining psychological processes. Journal of Personality and Social Psychology, 89, 845-851. doi:10.1037/0022-3514.89.6.845

Srivastava, S. (2010). The Five-Factor Model describes the structure of social perceptions. Psychological Inquiry, 21, 69-75. doi:10.1080/10478401003648815

Srivastava, S., Tamir, M., McGonigal, K. M., John, O. P., \& Gross, J. J. (2009). The social costs of emotional suppression: A prospective study of the transition to college. Journal of Personality and Social Psychology, 96, 883-897. doi:10.1037/a0014755

Tiedens, L. Z. (2001). Anger and advancement versus sadness and subjugation: The effect of negative emotion expressions on social status conferral. Journal of Personality and Social Psychology, 80, 86-94. doi:10.1037//0022-3514.80.1.86

Vazire, S. (2010). Who knows what about a person? The Self-Other Knowledge Asymmetry (SOKA) model. Journal of Personality and Social Psychology, 98, 281-300. doi: $10.1037 / \mathrm{a} 0017908$ 
Wiggins, J. S., \& Trapnell, P. D. (1996). A dyadic-interactional perspective on the five-factor model. In J. S. Wiggins (Ed.), The five-factor model of personality: Theoretical perspectives (pp. 88-162). New York, NY: Guilford Press. 


\section{Footnotes}

${ }^{1}$ To check whether the mediating effects of personality trait judgments overlapped with mediating effects of perceived emotion experience and expression, we also ran the mediator models with those variables included (i.e., 4- and 6-mediator models, respectively). In both of those models the mediating paths via the same trait judgments (extraversion and agreeableness in the first model; enthusiasm and compassion in the second model) were of similar magnitude and the CIs for those paths excluded zero. 
Table 1

Study 1 Means and Standard Deviations of Participants' Judgments of Targets, By Condition

\begin{tabular}{|c|c|c|c|c|c|c|c|c|}
\hline \multirow[b]{3}{*}{ Dependent Variable } & \multicolumn{4}{|c|}{ No Context } & \multicolumn{4}{|c|}{ Context } \\
\hline & \multicolumn{2}{|c|}{ Express } & \multicolumn{2}{|c|}{ Suppress } & \multicolumn{2}{|c|}{ Express } & \multicolumn{2}{|c|}{ Suppress } \\
\hline & Amu & Sad & $\mathrm{Amu}$ & Sad & Amu & $\mathrm{Sad}$ & $\mathrm{Amu}$ & $\mathrm{Sad}$ \\
\hline Extraversion & $\begin{array}{c}69.00 \\
(22.64)\end{array}$ & $\begin{array}{c}46.50 \\
(23.66)\end{array}$ & $\begin{array}{c}41.83 \\
(24.10)\end{array}$ & $\begin{array}{c}33.33 \\
(21.59)\end{array}$ & $\begin{array}{c}68.75 \\
(19.44)\end{array}$ & $\begin{array}{c}50.00 \\
(21.90)\end{array}$ & $\begin{array}{c}27.70 \\
(24.33)\end{array}$ & $\begin{array}{c}34.29 \\
(19.64)\end{array}$ \\
\hline Agreeableness & $\begin{array}{c}64.83 \\
(14.92)\end{array}$ & $\begin{array}{c}53.67 \\
(17.65)\end{array}$ & $\begin{array}{c}54.67 \\
(16.54)\end{array}$ & $\begin{array}{c}52.00 \\
(17.56)\end{array}$ & $\begin{array}{c}62.33 \\
(17.12)\end{array}$ & $\begin{array}{c}58.78 \\
(15.86)\end{array}$ & $\begin{array}{c}43.24 \\
(17.70)\end{array}$ & $\begin{array}{c}50.68 \\
(18.84)\end{array}$ \\
\hline Avoidant Attachment & $\begin{array}{c}39.33 \\
(15.01)\end{array}$ & $\begin{array}{c}50.89 \\
(14.66)\end{array}$ & $\begin{array}{c}55.94 \\
(13.86)\end{array}$ & $\begin{array}{c}60.72 \\
(14.31)\end{array}$ & $\begin{array}{c}36.43 \\
(14.48)\end{array}$ & $\begin{array}{c}47.07 \\
(15.52)\end{array}$ & $\begin{array}{c}62.16 \\
(15.09)\end{array}$ & $\begin{array}{c}55.24 \\
(17.52)\end{array}$ \\
\hline Anxious Attachment & $\begin{array}{c}45.78 \\
(15.40)\end{array}$ & $\begin{array}{c}55.44 \\
(13.77)\end{array}$ & $\begin{array}{c}53.78 \\
(14.81)\end{array}$ & $\begin{array}{c}56.83 \\
(14.73)\end{array}$ & $\begin{array}{c}45.05 \\
(14.93)\end{array}$ & $\begin{array}{c}54.50 \\
(13.04)\end{array}$ & $\begin{array}{c}56.81 \\
(14.56)\end{array}$ & $\begin{array}{c}54.00 \\
(12.31)\end{array}$ \\
\hline Interest in Affiliating & $\begin{array}{c}60.58 \\
(17.30)\end{array}$ & $\begin{array}{c}48.13 \\
(19.19)\end{array}$ & $\begin{array}{c}44.84 \\
(20.48)\end{array}$ & $\begin{array}{c}39.38 \\
(18.58)\end{array}$ & $\begin{array}{c}64.73 \\
(16.43)\end{array}$ & $\begin{array}{c}54.28 \\
(18.32)\end{array}$ & $\begin{array}{c}35.81 \\
(19.90)\end{array}$ & $\begin{array}{c}41.13 \\
(19.07)\end{array}$ \\
\hline
\end{tabular}

Note. Means and standard deviations (in parentheses) for the five dependent variables have a theoretical range from 0 to 100 . Amu $=$ Amusement; Sad $=$ Sadness. 
Table 2

Study 2 Means and Standard Deviations of Participants' Judgments of Targets, By Condition

\begin{tabular}{|c|c|c|c|c|c|c|c|c|c|c|}
\hline \multirow[b]{3}{*}{ Dependent Variable } & \multicolumn{5}{|c|}{ No Context } & \multicolumn{5}{|c|}{ Context } \\
\hline & \multicolumn{2}{|c|}{ Express } & \multicolumn{2}{|c|}{ Suppress } & \multirow[b]{2}{*}{$\mathrm{Neu}$} & \multicolumn{2}{|c|}{ Express } & \multicolumn{2}{|c|}{ Suppress } & \multirow[b]{2}{*}{$\mathrm{Neu}$} \\
\hline & Amu & Sad & Amu & Sad & & Amu & Sad & $\mathrm{Amu}$ & Sad & \\
\hline Extraversion & $\begin{array}{c}76.52 \\
(20.62)\end{array}$ & $\begin{array}{c}52.50 \\
(19.88)\end{array}$ & $\begin{array}{c}43.26 \\
(27.67)\end{array}$ & $\begin{array}{c}29.35 \\
(20.95)\end{array}$ & $\begin{array}{c}41.41 \\
(25.45)\end{array}$ & $\begin{array}{c}77.44 \\
(19.18)\end{array}$ & $\begin{array}{c}56.81 \\
(20.88)\end{array}$ & $\begin{array}{c}32.42 \\
(22.34)\end{array}$ & $\begin{array}{c}32.32 \\
(18.59)\end{array}$ & $\begin{array}{c}46.65 \\
(21.54)\end{array}$ \\
\hline Enthusiasm & $\begin{array}{c}77.00 \\
(15.89)\end{array}$ & $\begin{array}{c}54.61 \\
(19.01)\end{array}$ & $\begin{array}{c}50.43 \\
(24.68)\end{array}$ & $\begin{array}{c}36.30 \\
(20.49)\end{array}$ & $\begin{array}{c}45.74 \\
(21.90)\end{array}$ & $\begin{array}{c}77.24 \\
(15.15)\end{array}$ & $\begin{array}{c}59.47 \\
(19.62)\end{array}$ & $\begin{array}{c}42.11 \\
(19.89)\end{array}$ & $\begin{array}{c}39.35 \\
(17.47)\end{array}$ & $\begin{array}{c}50.24 \\
(20.09)\end{array}$ \\
\hline Assertiveness & $\begin{array}{c}57.30 \\
(13.79)\end{array}$ & $\begin{array}{c}50.13 \\
(14.96)\end{array}$ & $\begin{array}{c}46.04 \\
(17.85)\end{array}$ & $\begin{array}{c}39.96 \\
(17.48)\end{array}$ & $\begin{array}{c}46.00 \\
(16.64)\end{array}$ & $\begin{array}{c}57.93 \\
(16.33)\end{array}$ & $\begin{array}{c}52.97 \\
(16.33)\end{array}$ & $\begin{array}{c}37.72 \\
(16.73)\end{array}$ & $\begin{array}{c}41.95 \\
(17.20)\end{array}$ & $\begin{array}{c}48.29 \\
(14.76)\end{array}$ \\
\hline Agreeableness & $\begin{array}{c}68.91 \\
(18.16)\end{array}$ & $\begin{array}{c}56.74 \\
(19.75)\end{array}$ & $\begin{array}{c}56.63 \\
(20.43)\end{array}$ & $\begin{array}{c}48.37 \\
(19.20)\end{array}$ & $\begin{array}{c}51.85 \\
(20.29)\end{array}$ & $\begin{array}{c}67.07 \\
(14.60)\end{array}$ & $\begin{array}{c}58.64 \\
(18.74)\end{array}$ & $\begin{array}{c}54.07 \\
(17.79)\end{array}$ & $\begin{array}{c}49.49 \\
(17.71)\end{array}$ & $\begin{array}{c}52.74 \\
(17.35)\end{array}$ \\
\hline Compassion & $\begin{array}{c}69.22 \\
(14.21)\end{array}$ & $\begin{array}{c}64.65 \\
(18.86)\end{array}$ & $\begin{array}{c}54.74 \\
(18.74)\end{array}$ & $\begin{array}{c}44.70 \\
(18.26)\end{array}$ & $\begin{array}{c}50.39 \\
(19.12)\end{array}$ & $\begin{array}{c}70.33 \\
(14.11)\end{array}$ & $\begin{array}{c}67.24 \\
(20.30)\end{array}$ & $\begin{array}{c}49.67 \\
(18.69)\end{array}$ & $\begin{array}{c}48.01 \\
(20.90)\end{array}$ & $\begin{array}{c}52.52 \\
(16.46)\end{array}$ \\
\hline Politeness & $\begin{array}{c}62.91 \\
(14.99)\end{array}$ & $\begin{array}{c}56.04 \\
(16.55)\end{array}$ & $\begin{array}{c}60.35 \\
(15.10)\end{array}$ & $\begin{array}{c}56.30 \\
(16.32)\end{array}$ & $\begin{array}{c}57.96 \\
(15.07)\end{array}$ & $\begin{array}{c}60.49 \\
(13.24)\end{array}$ & $\begin{array}{c}60.08 \\
(15.10)\end{array}$ & $\begin{array}{c}61.79 \\
(14.53)\end{array}$ & $\begin{array}{c}56.83 \\
(14.83)\end{array}$ & $\begin{array}{c}56.10 \\
(14.45)\end{array}$ \\
\hline Avoidant Attachment & $\begin{array}{c}29.06 \\
(16.48)\end{array}$ & $\begin{array}{c}45.51 \\
(16.00)\end{array}$ & $\begin{array}{c}52.50 \\
(20.06)\end{array}$ & $\begin{array}{c}62.75 \\
(14.48)\end{array}$ & $\begin{array}{c}55.04 \\
(17.26)\end{array}$ & $\begin{array}{c}30.32 \\
(15.58)\end{array}$ & $\begin{array}{c}42.82 \\
(18.53)\end{array}$ & $\begin{array}{c}58.33 \\
(16.14)\end{array}$ & $\begin{array}{c}61.92 \\
(16.20)\end{array}$ & $\begin{array}{c}50.54 \\
(14.45)\end{array}$ \\
\hline
\end{tabular}




\begin{tabular}{|c|c|c|c|c|c|c|c|c|c|c|}
\hline Anxious Attachment & $\begin{array}{c}41.63 \\
(19.52)\end{array}$ & $\begin{array}{c}54.49 \\
(15.81)\end{array}$ & $\begin{array}{c}49.82 \\
(15.98)\end{array}$ & $\begin{array}{c}53.01 \\
(16.85)\end{array}$ & $\begin{array}{c}52.14 \\
(14.28)\end{array}$ & $\begin{array}{c}42.38 \\
(18.03)\end{array}$ & $\begin{array}{c}54.17 \\
(14.57)\end{array}$ & $\begin{array}{c}55.76 \\
(17.06)\end{array}$ & $\begin{array}{c}53.56 \\
(15.29)\end{array}$ & $\begin{array}{c}50.30 \\
(13.68)\end{array}$ \\
\hline Interest in Affiliating & $\begin{array}{c}68.75 \\
(19.95)\end{array}$ & $\begin{array}{c}52.55 \\
(20.83)\end{array}$ & $\begin{array}{c}50.64 \\
(24.06)\end{array}$ & $\begin{array}{c}38.99 \\
(21.08)\end{array}$ & $\begin{array}{c}45.33 \\
(23.13)\end{array}$ & $\begin{array}{c}69.92 \\
(21.18)\end{array}$ & $\begin{array}{c}58.10 \\
(21.44)\end{array}$ & $\begin{array}{c}48.83 \\
(20.26)\end{array}$ & $\begin{array}{l}44.36 \\
(21.48)\end{array}$ & $\begin{array}{c}49.62 \\
(20.85)\end{array}$ \\
\hline
\end{tabular}

Note. Means and standard deviations (in parentheses) for the nine dependent variables have a theoretical range from 0 to 100 . Amu $=$

Amusement; Sad = Sadness; Neu = Neutral. 
Table 3

Effect Estimates and Confidence Intervals from Analyses Comparing Suppress and Neutral Targets in Study 2

\begin{tabular}{|c|c|c|c|c|c|c|c|c|}
\hline \multirow[b]{2}{*}{$\begin{array}{l}\text { Condition \& } \\
\text { Dependent Variable }\end{array}$} & \multicolumn{4}{|c|}{ No Context } & \multicolumn{4}{|c|}{ Context } \\
\hline & $d$ & $D$ & $95 \% \mathrm{CI}$ & $\begin{array}{l}\text { Continuum } \\
\text { Hypothesis }^{\mathrm{a}}\end{array}$ & $d$ & $D$ & $95 \% \mathrm{CI}$ & $\begin{array}{l}\text { Continuum } \\
\text { Hypothesis }^{\mathrm{a}}\end{array}$ \\
\hline \multicolumn{9}{|l|}{ Suppress Sad } \\
\hline Extraversion & -0.52 & -11.93 & {$[-16.28,-7.58]$} & $\mathrm{N}$ & -0.71 & -14.29 & {$[-18.08,-10.50]$} & $\mathrm{N}$ \\
\hline Enthusiasm & -0.45 & -9.28 & {$[-13.27,-5.29]$} & $\mathrm{N}$ & -0.58 & -10.86 & {$[-14.31,-7.41]$} & $\mathrm{N}$ \\
\hline Assertiveness & -0.35 & -5.96 & {$[-10.15,-1.76]$} & $\mathrm{N}$ & -0.40 & -6.30 & {$[-9.66,-2.94]$} & $\mathrm{N}$ \\
\hline Agreeableness & -0.18 & -3.36 & {$[-7.72,1.00]$} & $\mathrm{N}$ & -0.19 & -3.24 & {$[-7.14,0.66]$} & $\mathrm{N}$ \\
\hline Compassion & -0.30 & -5.40 & {$[-9.15,-1.65]$} & $\mathrm{N}$ & -0.24 & -4.53 & {$[-8.76,-0.29]$} & $\mathrm{N}$ \\
\hline Politeness & -0.11 & -1.42 & {$[-4.80,1.95]$} & $\mathrm{Y}$ & 0.05 & 0.67 & {$[-2.27,3.62]$} & $\mathrm{Y}$ \\
\hline Avoidant Att. & 0.49 & 7.53 & {$[4.53,10.54]$} & $\mathrm{N}$ & 0.74 & 11.42 & {$[8.28,14.56]$} & $\mathrm{N}$ \\
\hline Anxious Att. & 0.06 & 0.93 & {$[-2.60,4.46]$} & $\mathrm{Y}$ & 0.22 & 3.21 & {$[-0.23,6.66]$} & $\mathrm{Y}$ \\
\hline Int. in Affiliating & -0.29 & -6.14 & {$[-9.91,-2.37]$} & $\mathrm{N}$ & -0.25 & -5.15 & {$[-9.18,-1.12]$} & $\mathrm{N}$ \\
\hline
\end{tabular}




\begin{tabular}{|c|c|c|c|c|c|c|c|c|}
\hline Extraversion & 0.07 & 2.68 & {$[-2.05,7.41]$} & Y & -0.65 & -14.22 & {$[-18.51,-9.92]$} & $\mathrm{N}$ \\
\hline Enthusiasm & 0.20 & 5.64 & {$[1.49,9.79]$} & $\mathrm{Y}$ & -0.41 & -8.16 & {$[-12.12,-4.21]$} & $\mathrm{N}$ \\
\hline Assertiveness & 0.003 & 0.30 & {$[-4.03,4.62]$} & $\mathrm{Y}$ & -0.67 & -10.55 & {$[-13.86,-7.24]$} & $\mathrm{N}$ \\
\hline Agreeableness & 0.23 & 5.37 & {$[0.84,9.91]$} & Y & 0.08 & 1.25 & {$[-3.22,5.72]$} & Y \\
\hline Compassion & 0.23 & 5.09 & {$[0.90,9.28]$} & $\mathrm{Y}$ & -0.16 & -2.95 & {$[-6.85,0.95]$} & $\mathrm{N}$ \\
\hline Politeness & 0.16 & 2.71 & {$[-1.13,6.54]$} & $\mathrm{Y}$ & 0.39 & 5.59 & {$[2.00,9.19]$} & $\mathrm{N}$ \\
\hline Avoidant Att. & -0.14 & -3.26 & {$[-6.39,-0.13]$} & $\mathrm{Y}$ & 0.51 & 7.85 & {$[4.73,10.97]$} & $\mathrm{N}$ \\
\hline Anxious Att. & -0.15 & -2.58 & {$[-6.27,1.11]$} & $\mathrm{Y}$ & 0.35 & 5.40 & {$[2.05,8.74]$} & $\mathrm{N}$ \\
\hline Int. in Affiliating & 0.22 & 6.19 & {$[1.71,10.66]$} & $\mathrm{Y}$ & -0.04 & -0.81 & {$[-5.26,3.64]$} & $\mathrm{N}$ \\
\hline
\end{tabular}

Note. Suppress-sad and neutral targets are compared (top half of table) and suppress-amuse and neutral targets are compared (bottom half of table). $\mathrm{Sad}=$ Sadness; Amuse $=$ Amusement; Att. = Attachment; Int. $=$ Interest; $d=$ The standardized effect size, calculated as the mean difference divided by the average within-cell standard deviation; $D=$ The unstandardized model-estimated mean difference; $95 \% \mathrm{CI}=$ The $95 \%$ confidence interval of $D$.

${ }^{\mathrm{a}}$ The continuum hypothesis states that judgments of suppress targets will fall between judgments of neutral and express targets. Y $=$ consistent with the continuum hypothesis; $\mathrm{N}=$ inconsistent with the continuum hypothesis. 
Table 4

Effect Estimates and Confidence Intervals from Joint Analyses of Study 1 and 2

Effect

$d$

$D$

$95 \% \mathrm{CI}$

Suppression

$\begin{array}{lccc}\text { Extraversion } & -1.32 & -27.88 & {[-30.15,-25.60]} \\ \text { Agreeableness } & -0.58 & -10.23 & {[-12.15,-8.31]} \\ \text { Avoidant Attachment } & 1.19 & 18.52 & {[16.64,20.40]} \\ \text { Anxious Attachment } & 0.32 & 5.02 & {[3.38,6.65]} \\ \text { Interest in Affiliating } & -0.81 & -16.63 & {[-18.97,-14.30]} \\ \text { Openness } & -0.69 & -11.35 & {[-13.07,-9.63]} \\ \text { Conscientiousness } & -0.30 & -5.15 & {[-7.03,-3.27]} \\ \text { Neuroticism } & 0.04 & 1.12 & {[-1.03,3.27]}\end{array}$

Suppression $\times$ Emotion

Extraversion

$-0.79$

$-17.49$

$[-22.33,-12.66]$

Agreeableness

$-0.34$

$-6.81$

$[-10.26,-3.37]$

Avoidant Attachment

0.57

9.86

[6.80, 12.93]

Anxious Attachment

0.69

10.64

$[7.61,13.66]$

Interest in Affiliating

$-0.39$

$-8.66$

$[-12.60,-4.72]$

Suppression $\times$ Context

Extraversion

$-0.34$

$-7.38$

[-11.93, -2.83]

Agreeableness

$-0.19$

$-4.22$

$[-8.05,-0.38]$

Avoidant Attachment

0.22

3.47

$[-0.29,7.24]$ 


$\begin{array}{lccc}\text { Anxious Attachment } & 0.14 & 1.99 & {[-1.29,5.26]} \\ \text { Interest in Affiliating } & -0.21 & -5.18 & {[-9.85,-0.52]} \\ \text { uppression } \times \text { Emotion } \times \text { Context } & & & \\ \text { Extraversion } & -0.49 & -10.88 & {[-20.55,-1.21]} \\ \text { Agreeableness } & -0.05 & -1.21 & {[-8.11,5.68]} \\ \text { Avoidant Attachment } & 0.35 & 6.75 & {[0.63,12.88]} \\ \text { Anxious Attachment } & 0.31 & 4.99 & {[-1.06,11.04]} \\ \text { Interest in Affiliating } & -0.24 & -5.79 & {[-13.68,2.10]}\end{array}$

Note. $d=$ The standardized effect size, calculated as the mean difference divided by the average within-cell standard deviation; $D=$ The unstandardized model-estimated mean difference; $95 \%$ CI $=$ The $95 \%$ confidence interval of $D$. 
No Context
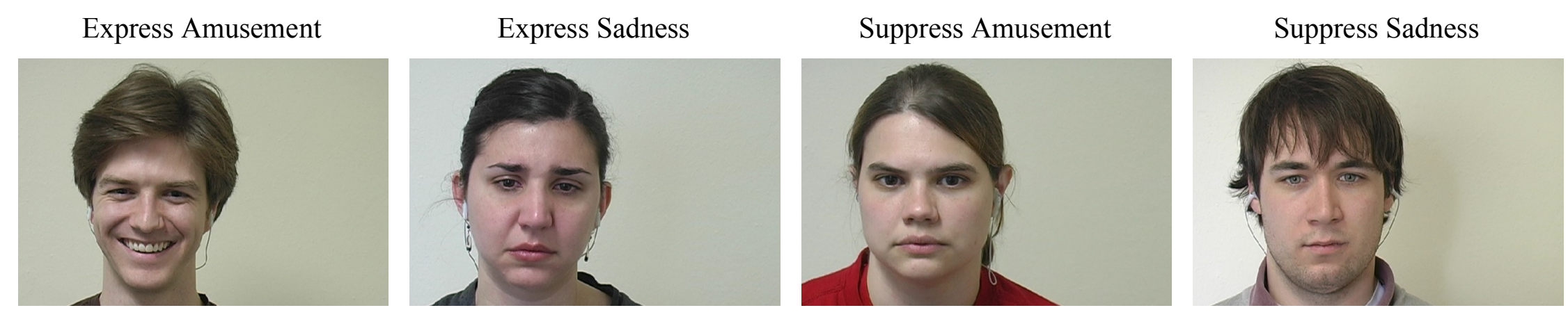

\section{Context}

Express Amusement

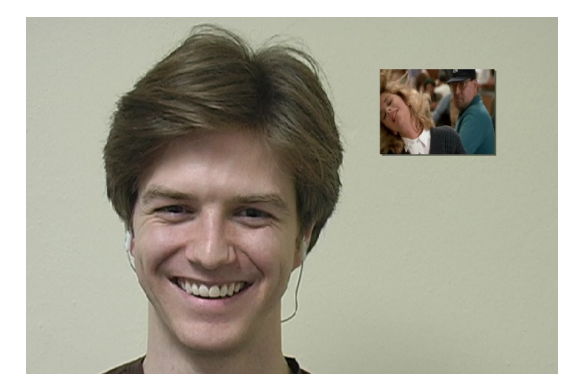

Express Sadness

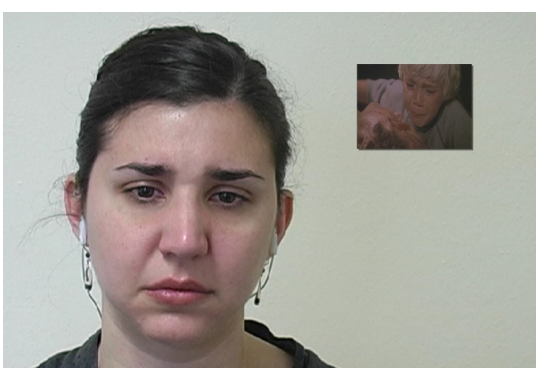

Suppress Amusement

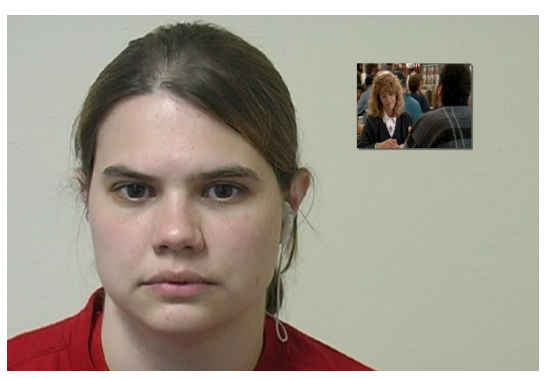

Suppress Sadness

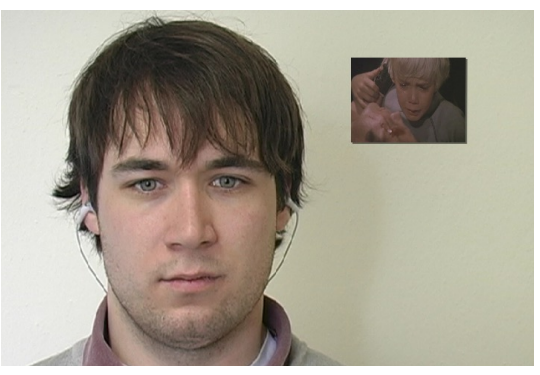

Figure 1. Still images from the video stimuli for Study 1. 
A

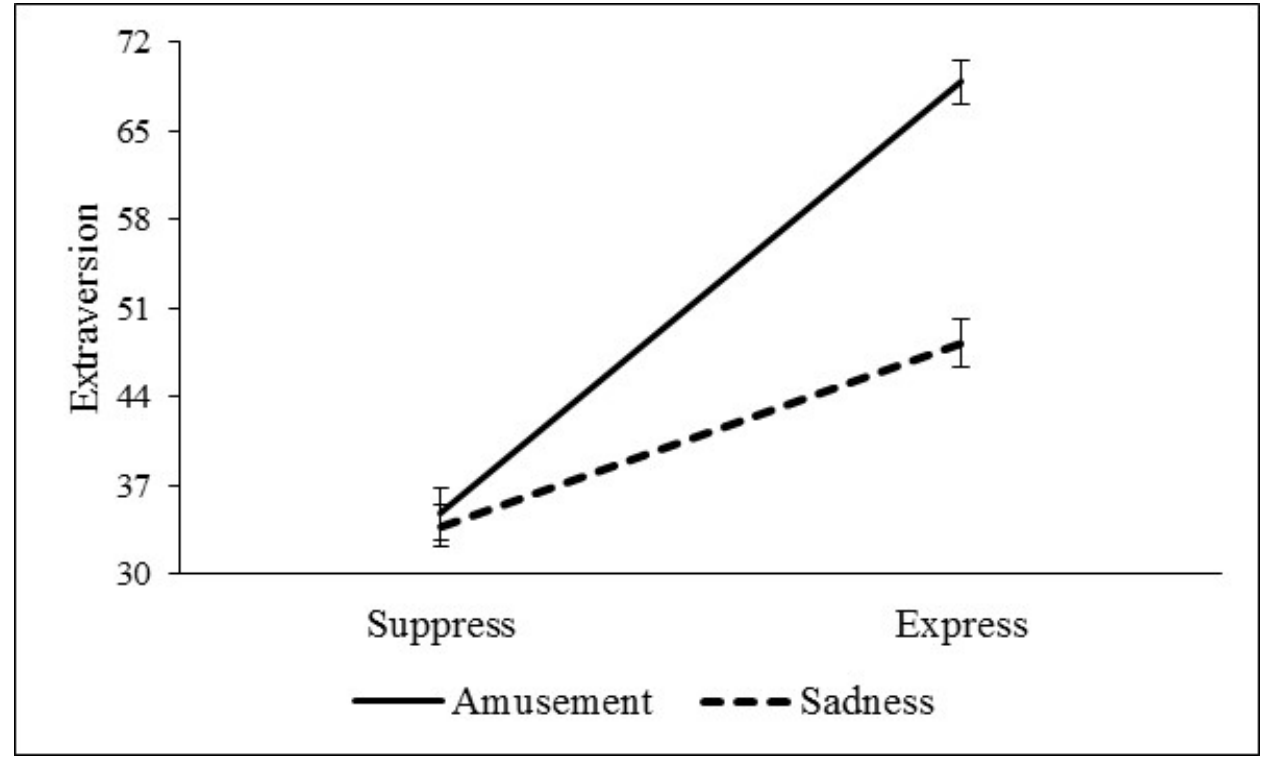

B

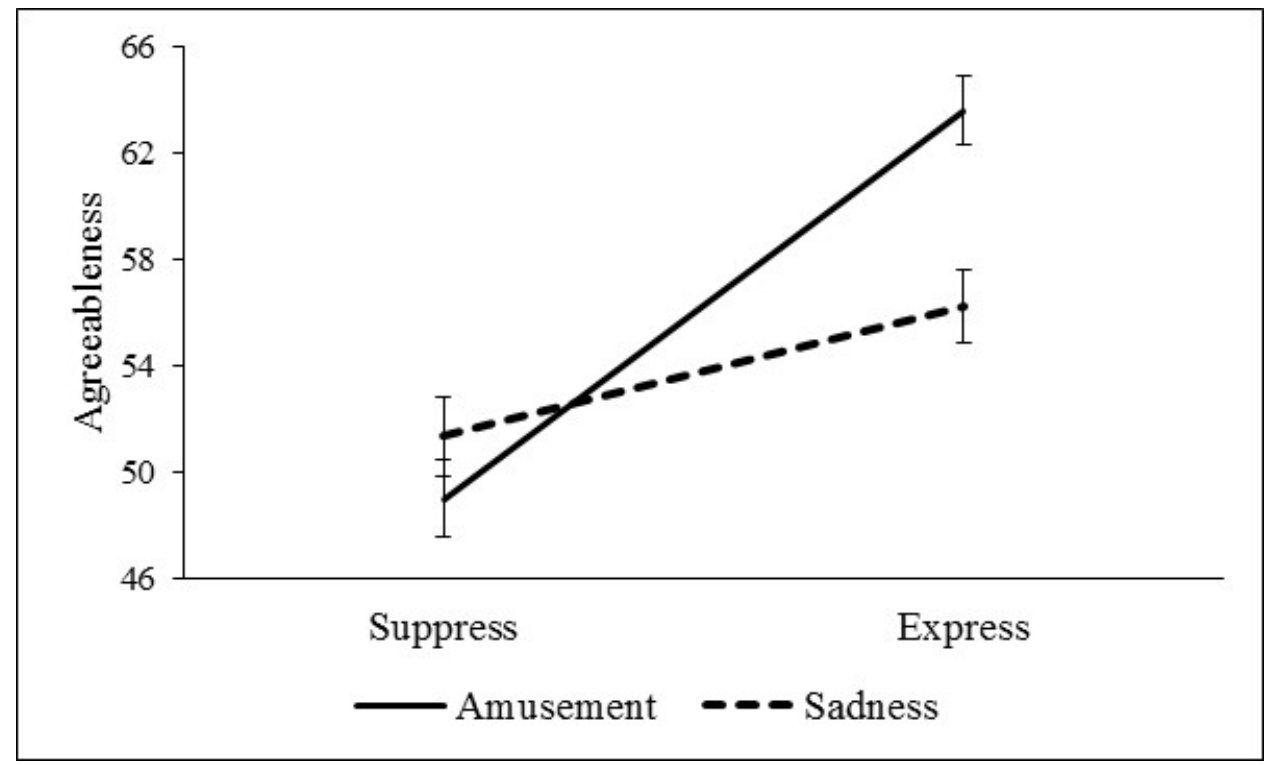

Figure 2. Suppression-by-emotion interaction for personality trait judgments of extraversion (panel A) and agreeableness (panel B) from Study 1. Means are plotted, and error bars represent standard errors. Values on the y-axis have a theoretical range from 0 to 100 . 
A

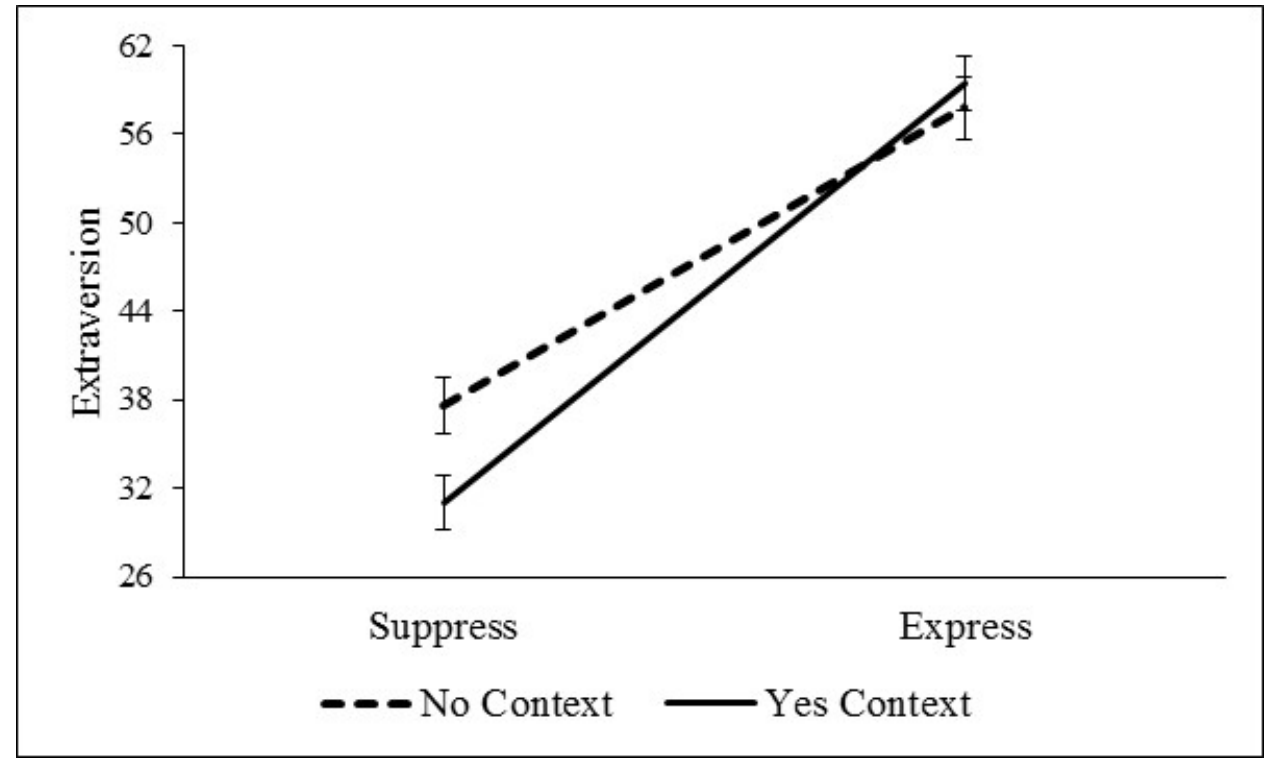

B

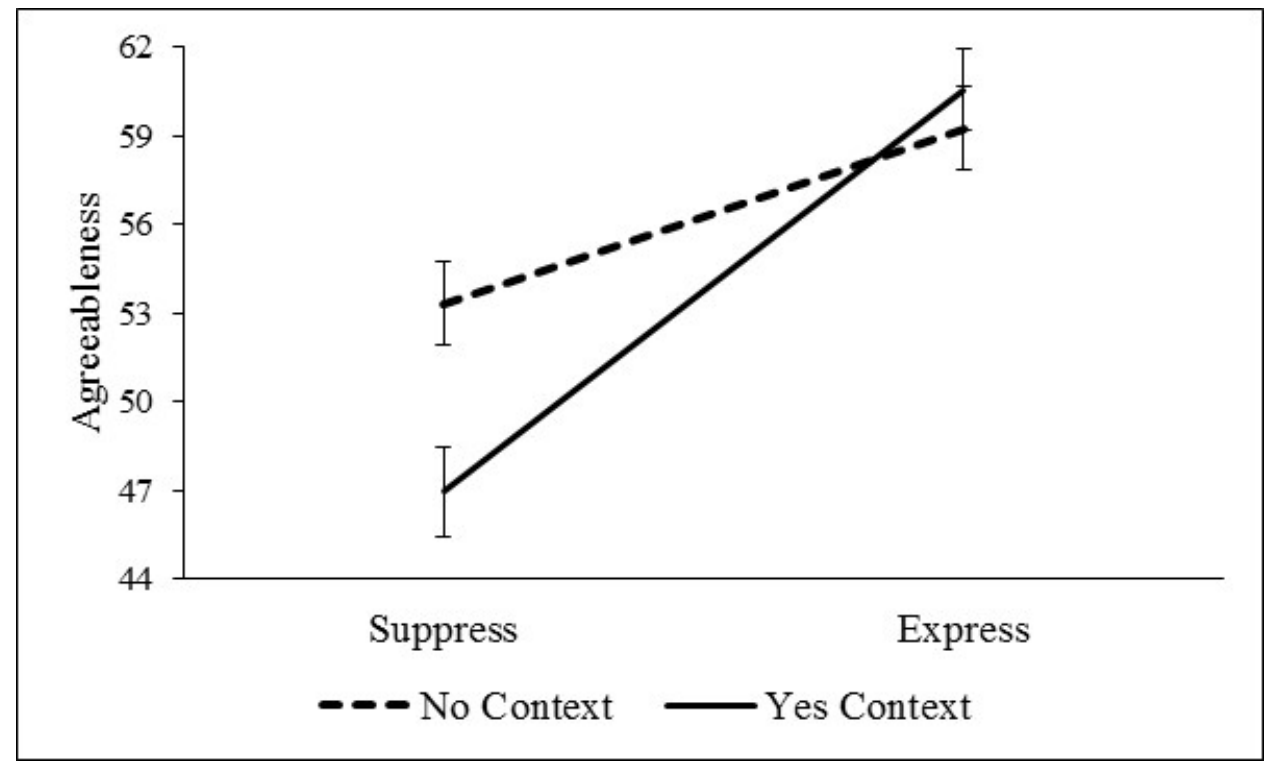

Figure 3. Suppression-by-context interaction for personality trait judgments of extraversion (panel A) and agreeableness (panel B) from Study 1. Means are plotted, and error bars represent standard errors. Values on the y-axis have a theoretical range from 0 to 100 . 
A

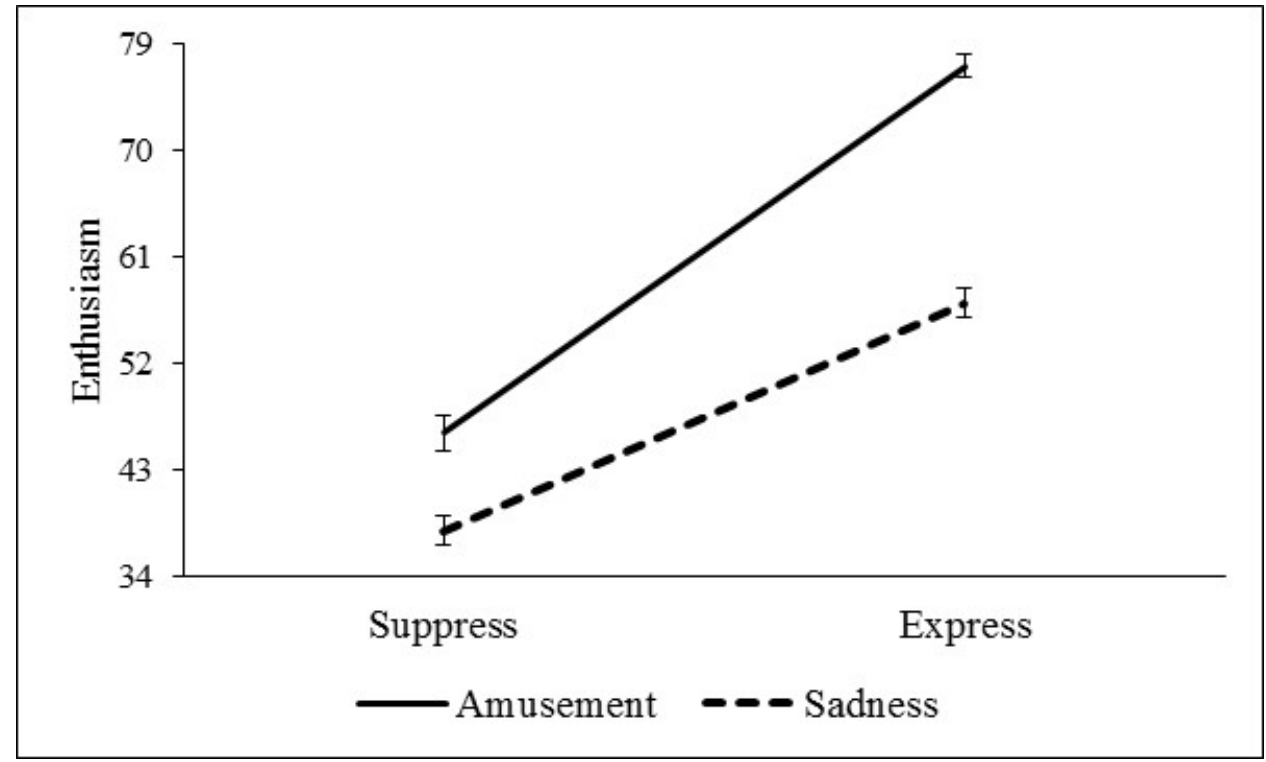

B

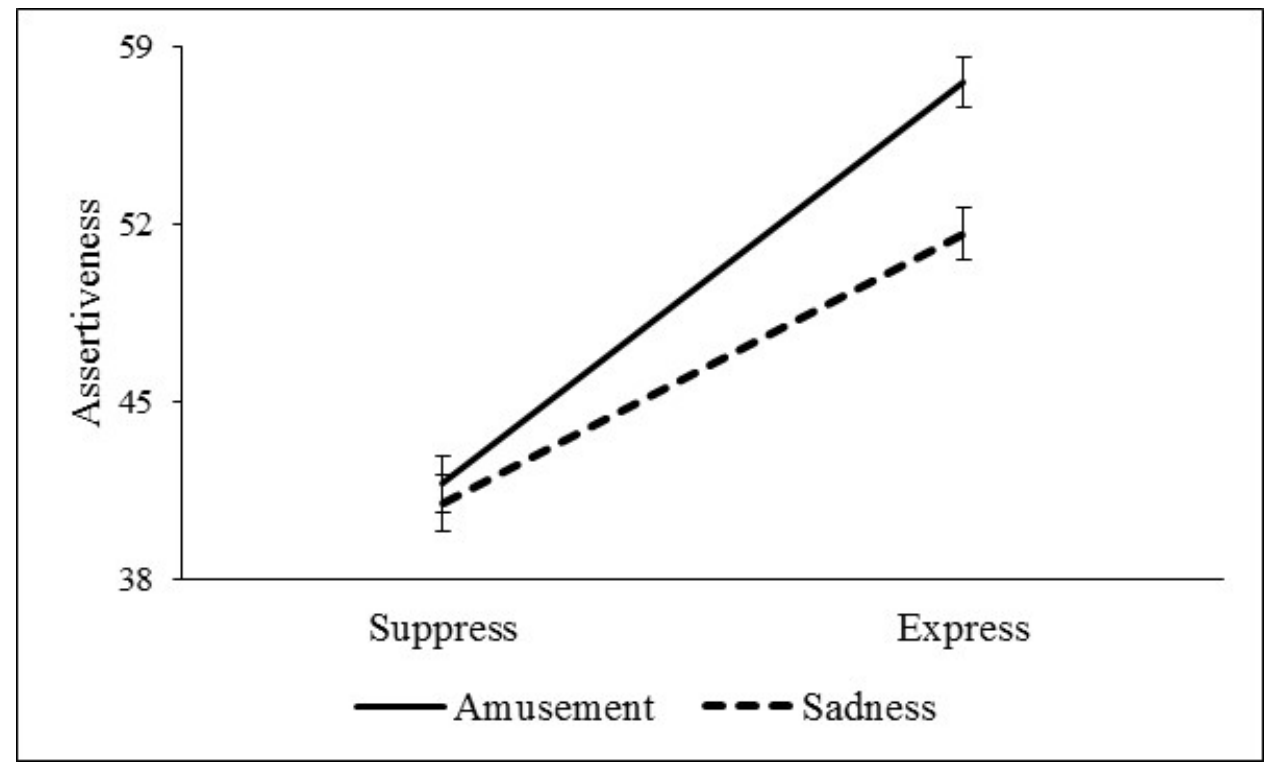

Figure 4. Suppression-by-emotion interaction for personality aspect judgments of enthusiasm (panel A) and assertiveness (panel B) from Study 2. Means are plotted, and error bars represent standard errors. Values on the y-axis have a theoretical range from 0 to 100 . 
A

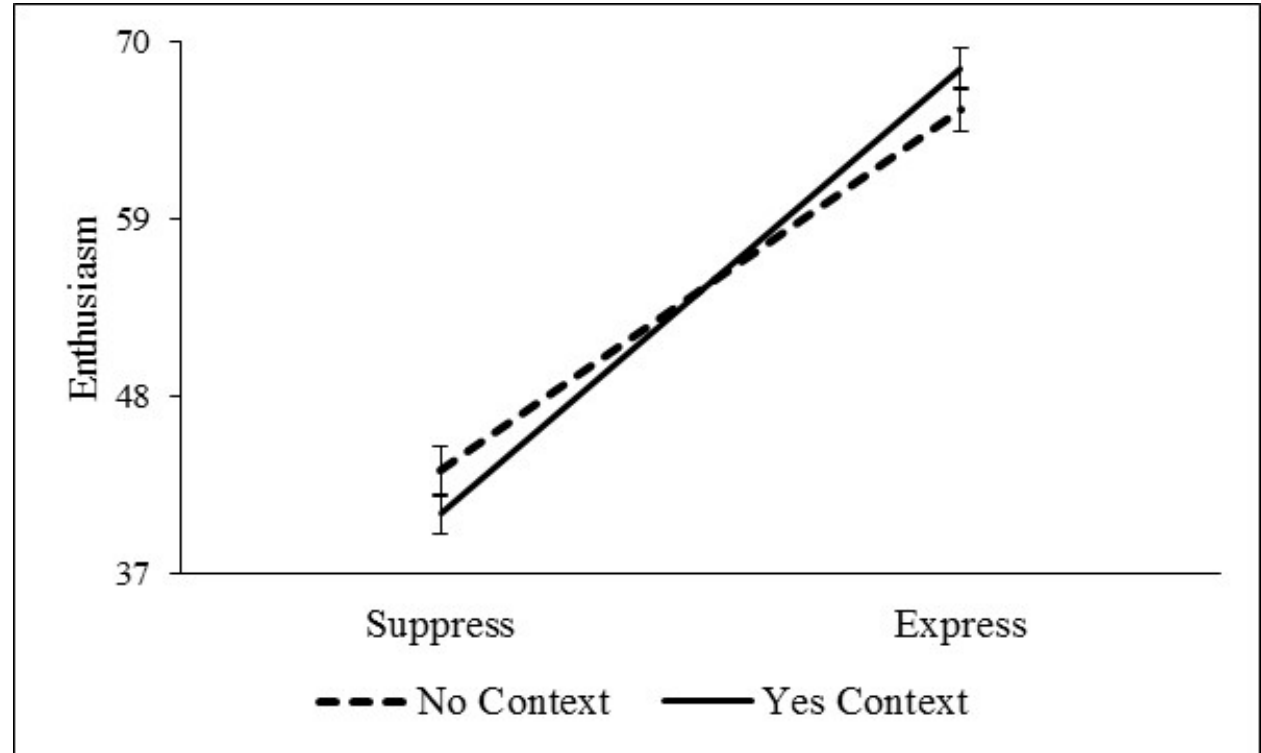

B

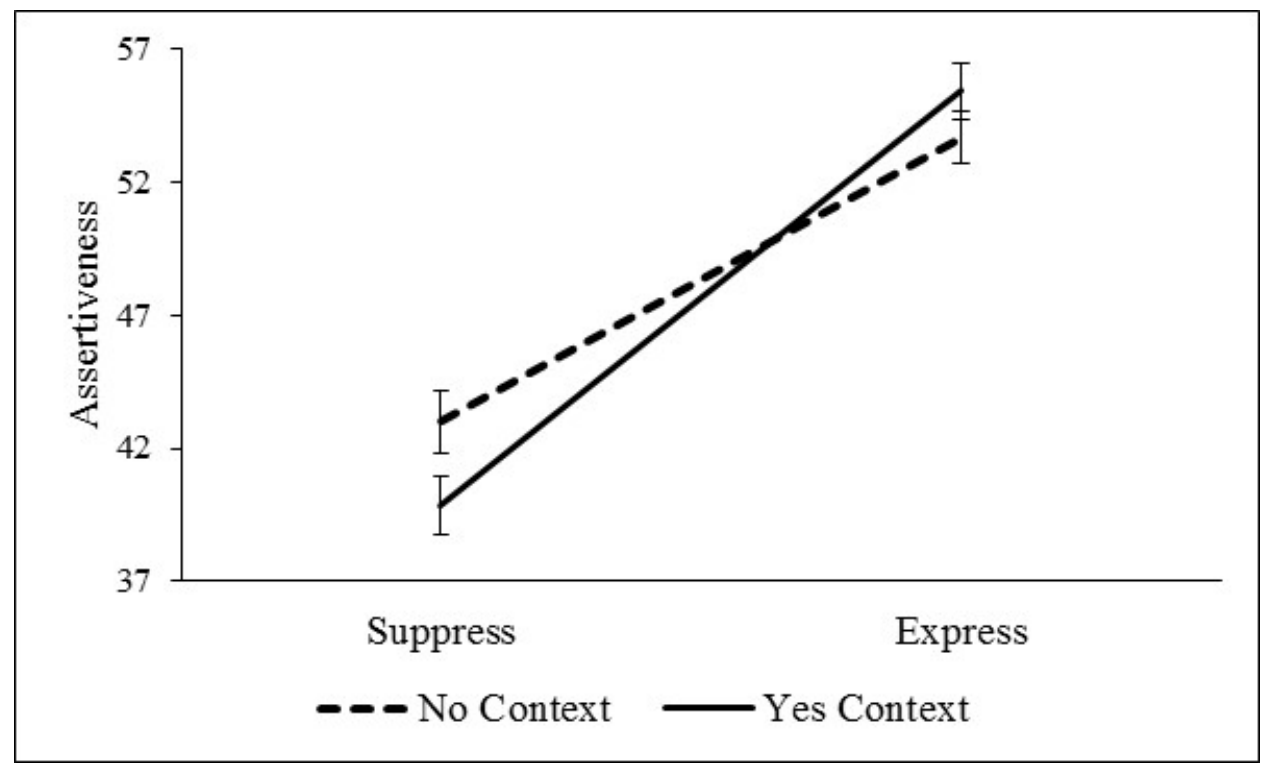

Figure 5. Suppression-by-context interaction for personality aspect judgments of enthusiasm (panel A) and assertiveness (panel B) from Study 2. Means are plotted, and error bars represent standard errors. Values on the y-axis have a theoretical range from 0 to 100 . 